\title{
TIENDAS Y CONSUMO EN PUNTA ARENAS (1900-1917) REFLEXIONES SOBRE LA PUBLICIDAD COMO FUENTE HISTÓRICA
}

\author{
JACQUELINE DUSSAILLANT-CHRISTIE
}

\begin{abstract}
RESUMEN
A comienzos del siglo XX la prensa puntarenense era uno de los medios de información y de difusión de ideas y conocimientos más relevantes de la zona magallánica. Parte importante de sus páginas estaba cubierta de avisos publicitarios, lo que además de demostrar la relevancia que éstos tenían para su financiamiento, da cuenta del grado de desarrollo de la actividad económica de la zona y del potencial que importadores, productores y comerciantes vieron en la inserción de anuncios para la promoción de sus actividades. Este artículo reconstruye el escenario comercial en el que se desenvolvían los habitantes de la ciudad de Punta Arenas entre 1900 y 1917 a través de la información de puntos de venta y bienes de consumo que se desprende de los avisos publicitarios publicados en El Comercio, La Unión, Chile Austral, Eco de la Guerra y The Magellan Times. Con ello se pretende también demostrar la riqueza documental de la publicidad y contribuir con una reflexión teórica y propuestas metodológicas al empleo de la publicidad como fuente para la historia.
\end{abstract}

PALABRAS CLAVE: Punta Arenas, historia, publicidad, fuente histórica, comercio, consumo.

\section{STORES AND CONSUMPTION IN PUNTA ARENAS (1900-1917). REFLECTIONS ON ADVERTISING AS A HISTORICAL SOURCE}

\begin{abstract}
In the early twentieth century the Punta Arenas press was one of the most important media in the Magellanic area. An important part of its pages was covered with advertisements, which besides demostrating their significance as a financing source also shows the degree of development of economic activities in the area and the potential that importers, producers and traders saw on advertisement as a promoter of their activities. This article reconstructs the commercial scenario in which the inhabitants of the city of Punta Arenas lived and purchased between 1900 and 1917 using information about shops and consumer goods that emerges from advertisements published in El Comercio, La Unión, Chile Austral, Eco de la Guerra and The Magellan Times. We also seek to show the wealth of advertising as source

a Profesora Asociada e investigadora del Centro de Investigación y Documentación (CIDOC) de la Facultad de Humanidades y Comunicaciones de la Universidad Finis Terrae. $X$ jdussaillant@uft.cl
\end{abstract}


of information and to contribute to a theoretical and methodological discussion on the use of advertising as a historical source.

KEY WORDS: Punta Arenas, history, advertising, historical source, trade, consumption.

\section{INTRODUCCIÓN}

En los primeros meses del año 1914 el periódico puntarenense The Magellan Times publicó un aviso de un colegio inglés para niños a cargo de J. C. Carter, para anunciar que las clases comenzaban el 2 de marzo. Agregaba que su tarifa era de $\$ 25$ por mes -esto es, el doble de una suscripción anual al mismo periódico-, que los cursos de música y español eran "extras" y que se ofrecían dos becas a los camp boys, o chicos que vivían en las haciendas. Por alguna razón, en junio del mismo año el señor Carter optó por cambiar la tónica de su aviso, dejando de lado el énfasis informativo para entregar a cambio argumentos persuasivos en la forma de dos promesas. La primera, muy concreta y práctica, era que los niños recibirían un "especial entrenamiento para la vida comercial", mientras que la segunda se limitaba a cuatro palabras con enorme poder sugestivo: Keep Your Boys British ${ }^{1}$. Aunque ambos avisos eran breves y no ocupaban más que una pequeña porción de la página en la que fueron publicados, son señal suficiente del potencial que tiene la publicidad como fuente para la historia tanto por la información que proporciona como por las preguntas que sugiere.

Aunque por siglos los historiadores han privilegiado las fuentes escritas por sobre otras, fue hacia mediados del siglo XX que la situación comenzó a cambiar al ampliarse el abanico de temáticas susceptibles de ser historiadas, lo que hizo necesario abrir también nuevos horizontes documentales. Pese a que esto ha significado elevar a la categoría de "testimonio histórico" a casi cualquier rastro del pasado, no siempre ha ido de la mano con reflexiones o discusiones teóricas que brinden apoyo epistemológico y metodológico a dichas nuevas fuentes. En consecuencia, la extensión del espectro temático y fontal sigue representando un interesante desafío para el historiador tanto en su evaluación previa como en su uso posterior. En este contexto, consideramos que existen suficientes razones para poner en valor a la publicidad como materia prima para el historiador. En primer lugar, porque debido a que su uso como fuente primaria para estudios históricos es muy reciente, son aún escasas las reflexiones metodológicas y epistemológicas que lo sustentan. Luego, porque nos mueve la convicción de que es un tipo de documento especialmente rico en datos que suelen ser difíciles de obtener mediante otros recursos y que pueden hacer interesantes aportes a la historia comercial, urbana, social y cultural. Por último, la publicidad es parte relevante de la sociedad moderna de la misma manera en que los periódicos eran a comienzos del siglo $\mathrm{XX}$ un vehículo privilegiado de difusión de ideas y conocimientos. No en vano Fernand Braudel señalaba que en ellos el lector se reconoce por ser una suerte de historia escrita día tras día (Braudel, 2002). Dicha afirmación es perfectamente válida también para los avisos publicitarios que llegaban a quienes hojeaban sus páginas. De hecho, esos anuncios no sólo hablan de productos y marcas, también expresan comportamientos, estilos y roles de diferentes elementos que conforman nuestra cultura (Pollay, 1985, p. 24); además de costumbres y configuraciones sociales, entornos y experiencias cotidianas (Clampin, 2013). De ahí que su estudio sistemático sea un significativo aporte orientado a conocer más de las sociedades del pasado, que es precisamente la línea en la que este artículo busca contribuir.

Nuestro propósito es demostrar la riqueza de los avisos publicitarios como fuente para la historia mediante un ejercicio concreto consistente en extraer de ellos tanto información explícita como implícita acerca de Punta Arenas y sus habitantes a comienzos del siglo XX. Para ello se comenzará por evaluar en qué medida los anuncios publicitarios reúnen los criterios que se le exige a cualquier fuente histórica, para lo cual se enfrentará a la publicidad a lo que suele denominarse crítica de fuente. Luego 
veremos qué tipo de datos y preguntas arroja sobre Punta Arenas y sus habitantes el estudio de los avisos publicados en El Comercio, La Unión, Chile Austral, Eco de la Guerra y el diario The Magellan Times que en conjunto permiten cubrir el período $1900-1917^{2}$. Se han considerado todos los avisos publicitarios, incluidos los "clasificados" que en La Unión y Chile Austral aparecían bajo el título de "avisos sobre crónica", de El Comercio como "avisos económicos" y en The Magellan Times de 1914 como anuncios profesionales.

\section{LA CRÍTICA DE FUENTES Y LA PUBLICIDAD}

Si la crítica externa a la que es sometido un documento histórico examina fundamentalmente su autenticidad, para lo cual fija su atención en la materialidad, escritura y procedencia, entre otras cuestiones, los avisos que aparecen impresos en diarios y revistas no revisten mayor duda al respecto. Tales medios están fechados, muchas veces presentan más de un ejemplar existente en diferentes archivos o bibliotecas y se publican, además, con una cierta frecuencia. Es difícil, por lo mismo, que nos hallemos en tal contexto con un aviso materialmente "falso". En este caso, se trata de periódicos que se publicaron en Punta Arenas con una periodicidad diaria o semanal y cuyos avisos publicitarios en su mayoría estaban firmados por comerciantes y profesionales conocidos en la ciudad, lo que se constituiría en su "certificado de presencia" (Barthes, 1999, p. 151). La crítica interna, en cambio, que se dedica fundamentalmente al contenido del documento y centra su atención principalmente en la veracidad, la exactitud de los datos o en sus grados de fiabilidad (Escandell, 1996, p. 171), requiere de mayor atención. Ello porque precisa pensar en torno a su objetividad en el sentido de preguntarse qué tan confiable es como un "reflejo" de lo que sucedió en el pasado (Salkind, 1999, p. 2010). En este caso, pese a que sí podría darse hipotéticamente el caso extremo de hallarnos frente a un aviso "falso" en cuanto a su contenido, aunque "materialmente" verdadero; la reflexión debe situarse más bien en torno a sus "grados" de credibilidad o, dicho de otro modo, de "ajuste a la realidad".

2 Se trabajó con los periódicos digitalizados que están disponibles en Memoria Chilena y en la Biblioteca digital

\section{El aviso publicitario: reflejo o ilusión}

Teniendo en cuenta que la eficacia persuasiva es el principio estructurante (Sánchez Corral, 1997, p. 16) de todo aviso publicitario, se entiende que su lenguaje sea esencialmente pragmático, aun si se trata de anuncios básicamente informativos. Si quien diseñó y/o publicó cada aviso tenía por objetivo dar a conocer $y / 0$ promover un producto y aumentar su venta, no es de extrañar que recurriera tanto a la exageración como a la omisión de argumentos y datos como parte de su estrategia. En otras palabras, dado que la distorsión de la realidad sería parte de su naturaleza, cabe preguntarse qué tan confiable puede ser la información que entrega acerca de Punta Arenas y sus habitantes. Tras este supuesto subyacen líneas argumentativas contrapuestas que han debatido esencialmente en torno a dos aspectos. El primero, en cuán ajustado o no es el discurso publicitario a la "realidad", y el segundo, hasta qué punto dicho discurso es capaz de influir en su audiencia. Algunos señalan que la publicidad es capaz de "moldear" a la sociedad porque tiene el "poder" para hacerlo, e incluso argumentan que la publicidad compite con otros agentes socializadores -como la iglesia y la escuela- en el momento de transmitir comportamientos, estilos e incluso principios morales. Esta es una idea propugnada por algunos publicistas y teóricos de las comunicaciones ya a fines del siglo XIX (Lantos, 1987, p. 106) y que aún contaba con algunos seguidores hacia la década de 1950, como es el caso de Marshall McLuhan (McLuhan, 2002, p. 1). En lo esencial, le otorgaban a la publicidad una fuerte capacidad modeladora de gustos y costumbres que incluso podía actuar sobre las personas a nivel "subliminal", tal como lo sostuvo Vance Packard en su libro The Hidden Persuaders en 1957. Argüían que la publicidad había podido generar movimientos "positivos", como el compromiso patriótico del ya célebre "I Want YOU for he U.S. Army" o hábitos de higiene, pero también otros negativos, tales como el tabaquismo o la valoración de determinados estereotipos sociales por sobre otros en términos de raza (Lantos, op. cit. p. 112). En dicha línea se inscribe, por lo tanto, la idea de que la publicidad crea necesidades, hábitos y hasta estereotipos sociales.

AIKE de la Universidad de Magallanes. 
Otros, más moderados en sus argumentos, sostienen que, si bien la publicidad tiene cierta capacidad modeladora de la sociedad, es sólo de manera indirecta. Esto debido principalmente a la fuerte influencia que ejerce sobre el financiamiento de los periódicos $-y$, por lo tanto, también sobre la política. Sin embargo, en la actualidad prima una mirada más escéptica acerca de su poder de cambio, en especial entre quienes mejor conocen sus potencialidades por estar dentro de la industria. Suelen citar el elocuente comentario que el destacado publicista David Ogilvy hizo al respecto: Creo que no es más que una herramienta de ventas, que sigue pero nunca lidera [los

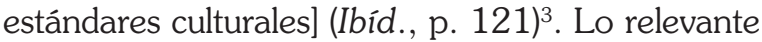
de todo este debate es que finalmente deriva en una aparente aporía, pues es difícil determinar los roles de causa y de efecto en el binomio publicidadsociedad. Esto equivale a preguntarse si un aviso de cigarrillos egipcios publicado en 1914 en las páginas de The Magellan Times estaba realmente fomentando el tabaquismo entre los magallánicos o sólo ofrecía una alternativa a los fumadores ${ }^{4}$. Como ya señalamos, los estudios actuales se inclinan más bien por una postura moderada que niega la capacidad modeladora de los avisos sobre la sociedad, con excepción, quizá, de algunos avisos dirigidos al público infantil. Así, la publicidad sería incapaz de crear nuevas necesidades, pero sí ayudaría a satisfacer viejas necesidades de nuevas maneras (Schudson, 1984) -con cigarrillos egipcios en este caso- $e$ incluso a acelerar procesos que ya estaban "en el ambiente", pues no sería sino una actividad comunicativa a través de la cual los cambios sociales son mediatizados (Leiss et al. 1986). Por dicha razón su mensaje no puede ser genuinamente "revolucionario" sino, por el contrario, tiende a ser más conservador en el sentido de reforzar ideologías y conceptos que ya predominan en el sistema social vigente (Souza, 2015).

Lo anterior es relevante en el momento de evaluar al aviso publicitario como fuente para la historia ya que el historiador necesariamente debe saber si se encuentra frente a un documento que refleja a la sociedad del pasado que desea conocer, si la refleja fielmente, de manera algo distorsionada

Las cursivas son nuestras.

The Magellan Times, 10 de junio de 1914. El aviso se o, por el contrario, no la refleja en absoluto pues es solo un mensaje que tenía como objetivo generar un cambio o modelar a dicha sociedad. Si ponemos atención a la imagen femenina que apareció en los avisos de los polvos desinfectantes Cooper en 1914 (Fig. 1), ¿habría que suponer que entonces las muchachas magallánicas vestían pantalones y trabajaban en la industria lanera? ¿O más bien habría que preguntarse por qué se empleó en dicho anuncio una figura tan aparentemente alejada de la realidad?

A nuestro entender, si bien no podría negarse la posibilidad de que sea tanto causa como efecto, "espejo" e "ilusión" (Fox, 1984, p. 64), el aviso publicitario especialmente ratifica, extiende y acelera aquello que ya está presente o "latente" en la sociedad. Esta idea de la publicidad como "espejo" de la sociedad retornó al debate a mediados de los años ochenta a propósito de la publicación de un artículo de Richard Pollay titulado "The Distorted Mirror", donde señaló que, si bien la publicidad refleja los valores culturales de una sociedad, lo hace de una manera selectiva, reforzando y haciendo eco de ciertas actitudes, comportamientos y valores de manera más frecuente que otros (Pollay, 1986, p. 33). El estudio de Pollay nos parece relevante porque nos recuerda que en los anuncios hay sólo "una parte" de la sociedad, pero también debido a que su reflexión acerca del tema de la distorsión concluye en que el estudio sistemático de una selección de avisos publicitarios es "excelente grano para el molino del historiador" (Ibíd., p. 31). La muchacha de la publicidad de los polvos Cooper que apareció en las páginas de The Magellan Times en 1914, por lo tanto, sería uno de los tantos "excelentes granos" y sólo sería realmente significativa como fuente si se la estudia no sólo de manera aislada, sino que también como parte de un conjunto relacionándola, por ejemplo, con las figuras femeninas que en el mismo año incluía el aviso de L.L Jacobs (Fig. 2).

Un segundo aspecto supuestamente débil de la publicidad como fuente y que se vincula con lo señalado hasta aquí, es que el historiador sólo es capaz de estudiar el aviso, vale decir, el mensaje y no su recepción. En otras palabras, se enfrenta a la compleja situación de que no puede conocer con

reducía a informar: Egyptian Cigarettes newly arrived from Cairo. Stubenrauch \& Co. 
exactitud los efectos de dicho mensaje sobre sus receptores, ni la actitud que tuvo dicha audiencia ante avisos como el de la muchacha de los pantalones. Sin embargo, nos parece que éste no es realmente un inconveniente exclusivo de la publicidad ya que son muchos los tipos de fuentes que en ocasiones enfrentan al historiador a una situación semejante de incertidumbre acerca de la recepción. Puede ocurrir con una carta, una novela o un discurso político, por señalar sólo algunos. Con todo, creemos que el escenario epistemológico sobre el cual puede apoyarse el anuncio como fuente es menos desesperanzador de lo que parece por tres razones. La primera, porque, contrariamente a lo que ocurre muchas veces con las fuentes empleadas por los historiadores, en este caso sí conocemos la intención de su emisor. En segundo lugar, porque existe la suficiente información contenida en estudios sobre la historia de la publicidad que nos guían en cuanto a su evolución en el tiempo, lo que nos permite distinguir las convenciones $y$ fórmulas habituales de los contenidos relevantes "reales". En otras palabras, dichos estudios actúan como una valiosa guía en el momento de utilizar la publicidad como fuente. Por último, partimos del supuesto de que una distorsión "desmesurada" no es realmente un riesgo ya que en estudios previos hemos comprobado que un aviso que se aleja abiertamente de la sociedad real, al no hallar eco en ella, termina por modificarse o por desaparecer (Dussaillant, 1993, 2011). Es decir, la permanencia de un anuncio o su cambio sugieren algo acerca de su receptividad, como es el caso de la modificación de estrategia publicitaria por parte del

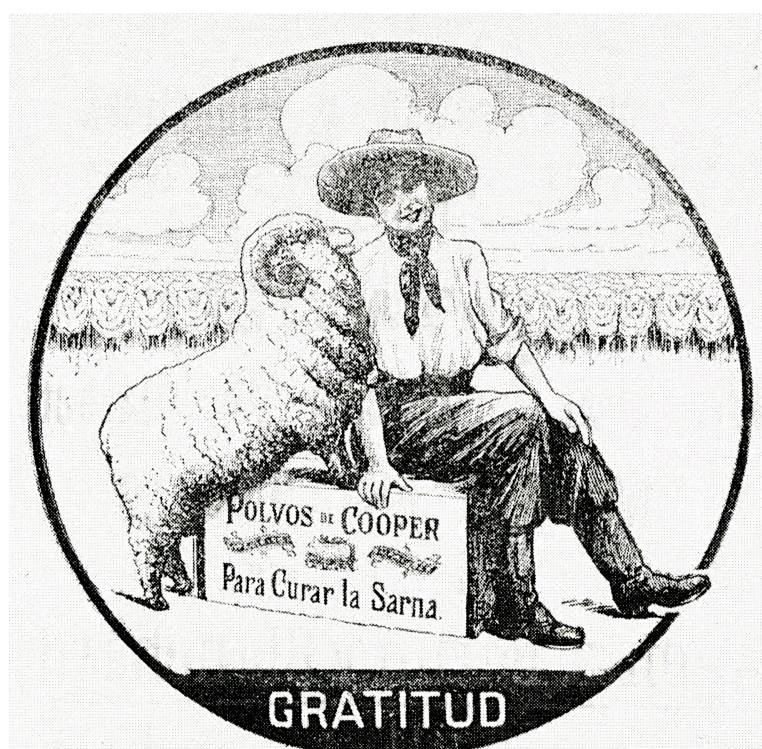

Fig. 1. Aviso de polvos Cooper en The Magellan Times, 1914.

mencionado señor J. C. Carter, lo que ciertamente podría atribuirse a que su proyecto educativo no estaba obteniendo los resultados esperados y por ello decidió jugarse cartas más persuasivas. Dicho de otro modo, en un aviso publicitario el emisor [...] presupone -o ha de presuponer si aspira a ser eficaz- la competencia interpretativa del receptor (Dussaillant, 2011, p. 18), de manera que este último no es ajeno al mensaje mismo. Más aún, creemos que el grado de distorsión que pone un aviso al visualizar lo retratado es en sí mismo un dato relevante para el historiador que estudia la realidad de la que forma parte, siempre que logre

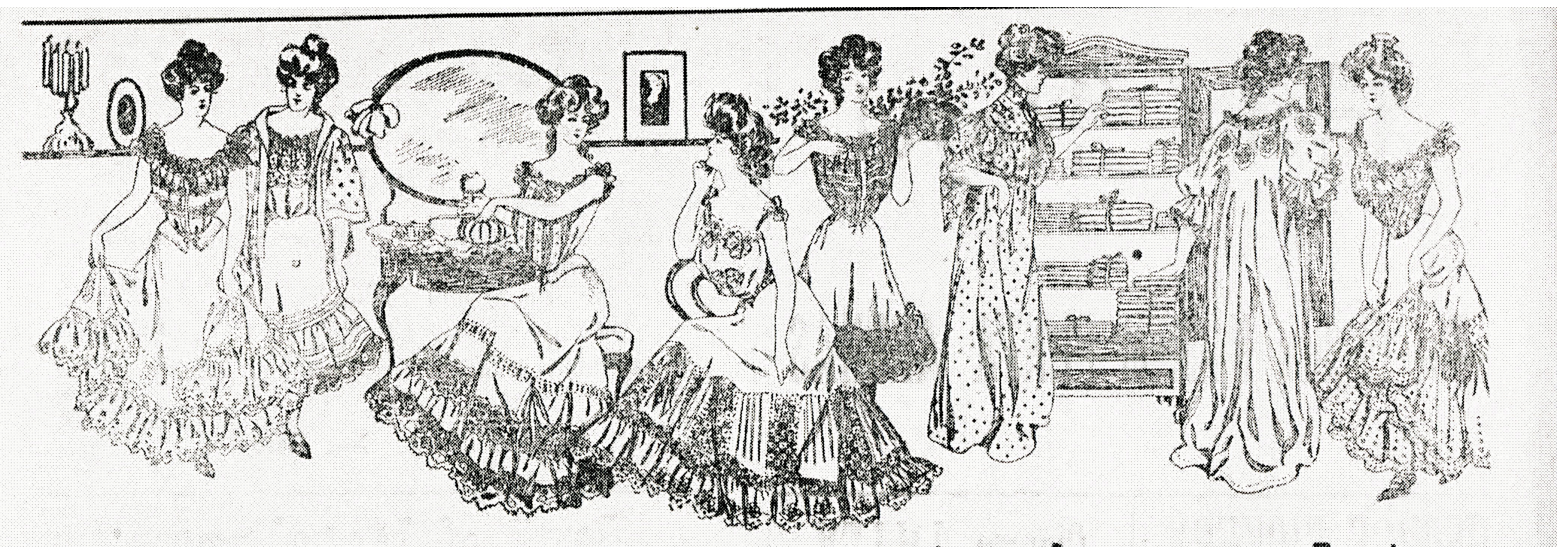

Fig. 2. Aviso de Casa Inglesa de L. L. Jacobs en The Magellan Times, 1914. 
advertirlo. Es el caso de la muchacha de los polvos Cooper, cuya vestimenta y contexto posiblemente no calzaban con la sociedad puntarenense en general, pero posiblemente sí en algún punto con la colonia británica a la que iba dirigido.

En definitiva, su valor como fuente para la historia sigue vigente porque es un discurso producido en un pasado, con determinados fines que son reconocibles para el historiador, $y$ realizado por quienes son contemporáneos a sus receptores al punto de que ambos pertenecen al mismo círculo de entendimiento. De manera similar a lo que algunos han señalado para el caso de la fotografía (Lara, 2005, p. 18), creemos que el aviso publicitario si bien no es una representación "literal" del presente del cual proviene es, sin duda, una "ventana" al pasado.

Crítica de fuente al aviso

publicitario en la prensa magallánica

Un buen punto de partida para evaluar críticamente a la publicidad inserta en la prensa como insumo para el historiador es conocer al ejemplar de prensa que la contiene y el rol que en ella cumple. En el caso de la prensa magallánica que aquí interesa, cabe señalar que El Comercio y el Chile Austral eran diarios informativos $e$ independientes, con un marcado énfasis comercial. El primero fue creado por Juan Bautista Contardi ${ }^{5}$ en el año 1900 y circuló hasta el año 1934, mientras que La Unión, de tendencia católica, también se extinguiría en ese mismo año tras veintidós años de existencia. El Eco de la Guerra, en tanto, tuvo una efímera existencia marcada, como su nombre lo indica, por el estallido de la Primera Guerra Mundial. Por último, The Magellan Times fue creado en 1914 por Charles Arthur Thomas Riesco, hijo de chileno y escocesa, y se vendía en Punta Arenas y en varias estancias magallánicas desde Tierra del Fuego hasta la provincia de Santa Cruz en Argentina durante la época de gloria de la industria lanera. Escrito en inglés, de periodicidad semanal y que alcanzó a tener un tiraje de mil copias, fue un instrumento de información y comunicación destinado principalmente a

5 Italiano que llegó a Punta Arenas en 1886, creó primero el periódico El Magallanes, y más tarde El Comercio. los miembros de la colonia británica de clase media-alta. Dejó de circular en 1936. Los datos anteriores son relevantes desde el momento en que podrían ayudar a comprender la naturaleza de los avisos que incluyen sus páginas, y el público al que iban dirigidos. De hecho, como advierte Pollay, la continuidad de la línea editorial de una publicación podría evitar errores de interpretación de los avisos publicitarios que pudieran deberse solamente a una cuestión editorial (Pollay, 1986. p. 26). En el caso que nos interesa, debe tenerse en cuenta, además de que iban dirigidos a una población alfabetizada que formaba parte de los sectores medio y alto de la sociedad puntarenense, el énfasis empresarial del periódico El Comercio y del Chile Austral, el contexto bélico en el que nació el Eco de la Guerra, el sello católico del periódico La Unión y la impronta británica de The Magellan Times. En el caso de The Magellan Times, la cuestión es teóricamente más clara ya que el propio C. Arthur Riesco lo definió en 1914 como a fortnightly newspaper devoted to the interests of the English Speaking People of Patagonia y en 1917 como the farthest South, British Newspaper. A weekly paper devoted to the interests of the Englishspeaking people in the Straits of Magellan, the Southern Argentine and Tierra del Fuego ${ }^{6}$. Así, a excepción de este último periódico que estaba dirigido a una audiencia más específica, los avisos insertos en todos los demás no sugieren una tendencia especial que pudiera atribuirse a sus lineas editoriales.

Coincidimos con la idea de que antes de hacer un estudio crítico de una fuente es preciso conocer previamente el papel histórico y valor social(Riego, 2001), económico, cultural o político que haya tenido en su momento, en especial si, como es el caso de la prensa y los avisos, fue puesto en circulación. En este caso, dado que buena parte de la superficie de las páginas de los periódicos revisados estaba cubierta por avisos, resulta evidente el importante rol que cumplía la publicidad como medio de financiamiento de dicha prensa, por una parte, y como fuente de utilidad práctica para avisadores y potenciales consumidores, por otra. Así, en 1900 y 1907

6 The Magellan Times, 6 de septiembre de 1917. Las cursivas son nuestras. 
las páginas de El Comercio estaban cubiertas en promedio en un $50 \%$ y $75 \%$ de avisos respectivamente, concentrados principalmente en la primera y última de sus cuatro páginas. Más acentuada era la situación del Chile Austral, ya que en los ejemplares estudiados del año 1908 casi el $80 \%$ del espacio disponible en sus ocho páginas, estaba absolutamente cubierto de avisos. La Unión, en tanto, en 1912 destinó, en promedio, el $63 \%$ de su superficie a los anuncios, el Eco de la Guerra el 50\%, mientras que en The Magellan Times los avisos fluctuaron entre 1914 y 1917 entre el 55\% al 60\%7. Cabe insistir que estos datos revelan la importante función que cumplía en esos comienzos del siglo XX el aviso publicitario para los periódicos magallánicos y sus lectores. Sin duda eran una vía importante no sólo de promoción de productos y servicios entre sus lectores, sino que, por la misma razón, una fuente relevante de conocimiento sobre la oferta existente en el mercado de la ciudad de la época. Esa misma información que por aquella vía llegaba a los habitantes de la Punta Arenas de comienzos del siglo es la que llega a nosotros hoy, proporcionándonos valiosa información sobre la ciudad, su comercio y sus habitantes.

Dicho lo anterior, es tiempo de plantear a la publicidad las preguntas habituales ${ }^{8}$ que se hacen en el momento de someter a una fuente a una "crítica interna" para conocer su proximidad "a los hechos", su independencia o tendenciosidad, su contexto $\mathrm{y}$, por último, también acerca de su autor. En relación con la pregunta acerca del tiempo que transcurrió entre el suceso y el momento en que se escribe el documento, podemos responder que el aviso publicitario se hace simultáneamente a los "hechos" de manera que su autor es prácticamente un "testigo presencial" u observador directo de su entorno y forma parte de la sociedad que, de un modo $\mathrm{u}$ otro, aparece representada en cada aviso. De hecho, el mismo diario invitaba a sus lectores a insertar sus avisos y a suscribirse al periódico, de manera que la simultaneidad del emisor, el receptor y el medio es innegable. Luego, a las preguntas sobre los intereses personales

7 Estos porcentajes corresponden al cálculo del promedio de los ejemplares revisados.

8 Hemos tomado como referencia para la elaboración de las o la intención que tiene el autor al escribir el "documento" sólo es posible responder que por la naturaleza misma del documento en cuestión -el aviso publicitario- su finalidad es clara y sabida: dar a conocer, ofrecer y promocionar un producto, establecimiento o servicio con la finalidad de generar en el receptor una inclinación hacia el mismo de manera de provocar en él un acto de compra. En otras palabras, busca vender. Por lo tanto, es intrínsecamente "tendencioso" ya que por muy simple que sea en la forma, está elaborado con ese objetivo.

En cuanto a la pregunta ¿cuándo y bajo qué circunstancias se creó el documento?, debe responderse tomando en cuenta tres dimensiones contextuales: la del periódico, la de la actividad publicitaria y la de la situación histórica. En lo que a la primera dimensión se refiere, puede señalarse que el contexto en el cual fue construido el documento no es un enigma si se considera que el aviso en este caso se inserta dentro de un medio informativo que sirve de marco contextual, pues nos señala el lugar, la fecha y muchos otros datos relevantes en el momento de situar cada anuncio publicitario. La segunda dimensión coincide con el "estado de la cuestión" de la actividad publicitaria en el que se origina cada anuncio. Para ello es esencial tener conocimiento de la historia de la publicidad y de la evolución de sus técnicas y estrategias a lo largo del tiempo, pues permite contextualizar cada aviso y así distinguir convenciones de casos excepcionales. En un estudio previo sobre los avisos publicitarios descubrimos que, en Chile, al igual que en Estados Unidos y muchos países europeos, la publicidad alcanzó fuerte presencia en los periódicos durante el siglo XIX, en especial a partir del último tercio (Dussaillant, 1993, op. cit.). Pero fue con el cambio de siglo cuando comenzó a profesionalizarse dicha actividad al aparecer las primeras agencias de publicidad, justo en el contexto del incremento de la competencia comercial que corría paralelamente al desarrollo de la industria, al creciente proceso de urbanización, al perfilamiento de la clase media como nuevo sujeto de consumo, al desarrollo de

preguntas a Moradiellos (1998), Carr (1999), Arostegui (2001) y Bloch (2001). 
la alfabetización, de la prensa, el transporte y las comunicaciones. Fue también entonces cuando se fue haciendo notoria la tendencia creciente entre los anunciadores que llevaban la vanguardia en el arte del avisaje a enfocar los avisos más en el consumidor que en el producto en sí mismo de manera de envolver el producto en un papel de sueños (Fox, 1984, op. cit. p. 150). Asimismo, la existencia de otros avisos en la misma edición del diario, y la comparación entre unos y otros también proporciona el contexto del estado de la cuestión en materia publicitaria; esto es, el conjunto sugiere las técnicas publicitarias y los argumentos persuasivos que se utilizan, dentro de los cuales es posible insertar cada uno de los anuncios que conforman el corpus estudiado. Dado que cualquier documento histórico exige conocer su lenguaje para poder comprenderlo, en este caso, se trata del lenguaje de la publicidad en el espacio y tiempo en que fue construido el mensaje. Baste señalar que los avisos que publicaron los periódicos magallánicos aquí revisados no difieren mayormente en lo formal y estratégico a los que aparecían en otros periódicos del país para las mismas fechas. La tercera dimensión, en tanto, exige insertar la información que se desprende de la publicidad con la historia de manera de tener en consideración, por ejemplo, desde la situación económica y política del país hasta el posible impacto de la Primera Guerra Mundial en las actividades puntarenenses al tratarse de una ciudad tan alejada espacialmente de dicho conflicto, pero tan emotivamente cercana al mismo debido a la existencia de una numerosa colonia inglesa.

Por último, ante preguntas tales como ¿quién lo hizo?, ¿qué se sabe de él? y ¿fue testigo presencial de los hechos?, ha de reconocerse que generalmente no sabemos nada acerca del autor "material" del anuncio publicitario, si entendemos por tal a quien realmente lo diseñó, redactó y dibujó. Sin embargo, sí conocemos algo del que podría resultar más relevante para nuestro propósito, su autor "intelectual", pues en ocasiones pone su nombre bajo el texto del aviso o simplemente se confunde con el nombre del establecimiento comercial o del producto.

En resumen, creemos que la publicidad, en este caso específicamente el aviso inserto en los diarios puntarenenses, no reviste mayores dudas con respecto a su naturaleza y valor como fuente, ya que aprueba sin dificultades los cuestionamientos básicos que se hacen frente a cualquier documento y que conocemos como "crítica de fuente".

\section{RIQUEZA FONTAL DE LOS AVISOS PUBLICITARIOS: PUNTA ARENAS Y SU COMERCIO ENTRE 1900 Y 1917}

Con el fin de evaluar la riqueza de la publicidad como fuente para la historia nos enfocaremos ahora en dar cuenta de la información que de ella se desprende. Para ello comenzaremos por la información explícita constituida por aquellos datos que para su obtención no se requieren mayores esfuerzos metodológicos y que hemos clasificado en tres grupos: actores, establecimientos $y$ productos. Cabe señalar que si bien por razones evidentes dichos datos en cualquier trabajo histórico deben ser cotejados y complementados con información que provenga de otras fuentes -como censos, matrículas de patentes, estadísticas comerciales, registros de viajeros y memorialistas, entre muchos otros- en este caso hemos decidido, en virtud del objetivo de este estudio, centrarnos sólo en la información que emana de los anuncios. Luego daremos cuenta de la información implícita que nos proporcionan los avisos publicados en la prensa seleccionada, que es aquella que requiere de algún tipo de metodología para poder "extraerla" del aviso, pues es menos evidente, más sutil y exige esfuerzos de interpretación mayores que la información explícita. En este caso, nos centraremos específicamente en las marcas de los productos y en los valores empleados como argumentos persuasivos.

\section{Actores}

Si los censos de población proporcionan información de gran utilidad para el historiador interesado en la sociedad de Punta Arenas, como que en 1907 de sus 12.199 habitantes un 35,7\% era extranjero (en su mayoría austrohúngaros, españoles y británicos) y algo más del $67 \%$ sabía leer (Comisión Central del Censo, 1907), los avisos publicitarios entregan una dimensión más humana a dichas cifras en la forma de nombres y apellidos 
de algunos profesionales y comerciantes que publicaron sus anuncios. Para el período estudiado hallamos a los dentistas Rogelio Sáez, F. E. Davis, Dr. Salcedo, Dr. Mardones, Anna Middleton y Luis A. Vallejo; los médicos Domingo Solo Zaldivar, Carlos Exss, Florencio Middleton, B. González Lagos, Luis A. Aguirre, J. Pais, López, Jermán Vegel, Dr. Dodds, Dr. Munizaga Ossandón, la médico obstetra Dra. Leonor López de Condell, las matronas Emma Amó de T., María J. Guzmán de Zenteno y Mrs. May Dawkins, la enfermera Whitaker $y$, por último, el pedicuro y masajista Herman Ullman. También insertaron sus avisos los abogados Ignacio Anguita Green, Luis A. Valencia C., Nibaldo Sanhueza, Humberto Fernández Godoy, Francisco Salas de la T., Esmaragdo Campaña, Ramón Luis Arriagada, Temístocles Urrutia Semir y Enrique Gallo. Entre los docentes, se cuentan el profesor de español Pedro Mayorga, el de piano y de canto Ángel Rossi y Mrs. Bridge, profesora de inglés, francés, alemán, piano, canto, danza y pintura. Esta última, además de llamar la atención por su gran versatilidad, publicó detalles que pueden resultar de interés, como el de que empleaba el "método Marchesi" para sus clases de canto. También identificamos a los agentes aduaneros Walter Dixon, Guillermo Wells, José Manuel Vega y Guillermo Wahlen; además del ingeniero civil H.C. Chetwood Aiken, los ingenierosarquitectos Antonio Allende R. y Antonio Beaulier, el martillero Pedro García Pereira, el carpintero F. Cano Vásquez, el boticario J. Robert, el pintor Daniel Cáceres y el pintor y decorador Alberto Margas. La mayor parte de los avisos de dichos profesionales eran inserciones muy escuetas $y$ sobrias, aunque en algunos casos ofrecen ciertos detalles que hacen posible reconocer el tipo de servicios que ofrecían. Así, por ejemplo, en 1914 un martillero invitaba a realizar ventas públicas y privadas, además de analizar títulos de propiedad, un ingeniero civil ofrecía sus servicios para trabajos topográficos y de perforación, mientras que los agentes de aduanas decían brindar su asistencia para el despacho y entrega rápida de mercancías. Esto último no es de extrañar si hacemos caso a Agustín Gómez García, quien ese mismo año recorrió la zona y observó que "la tramitación aduanera es muy larga y pesada" (Gómez García, 1914, p. 28). En cuanto a los médicos, por ejemplo, se ofrecían exámenes de rayos $\mathrm{X}$, aplicaciones eléctricas y masajes vibratorios, aplicación de ventosas, curación de callos y uñas encarnadas, además de estudios de laboratorio para saliva, jugos gástricos, orina, pus y sangre. No deja de llamar la atención que en ese temprano 1917 apareciera una médico obstetra, la doctora Leonor López de Condell, pues para entonces no era común aún que las mujeres siguieran carreras de medicina, lo que se corrobora con el censo de 1920 que para la zona de Magallanes no registra ningún médico de sexo femenino, de manera que permite suponer un error del censo, o bien el abandono de la ciudad o del ejercicio de médico de la señora López (Dirección General de Estadística, 1925). Además es interesante subrayar que entre los dentistas apareciera también otra mujer, Anna Middleton, mientras que todas las matronas $y$ parteras eran de sexo femenino.

Al localizar las direcciones que insertan los avisos de los profesionales mencionados sobre un plano de la ciudad podemos reconstruir parte de la "oferta profesional" de Punta Arenas de 1900-1917 e imaginar los recorridos por aquélla, pues dichos profesionales se concentraban aproximadamente en las cuatro cuadras alrededor de la plaza (Fig. 3). Advertimos que, según señalan varios anuncios, muchos de ellos vivían y atendían a sus clientes y pacientes en el mismo lugar, esto es, no se hacía una distinción clara entre el lugar de trabajo y de residencia. Esta misma tendencia es posible de observar en otras ciudades, en especial en el caso de los pequeños comerciantes que vivían en los "altos" de su negocio.

En cuanto a los comerciantes, banqueros y empresarios, hallamos a E. Pettersen, F.M. Bermúdez, Ferdinand Garnier, J. Robert, A. Chanfreau, Alberto Margas, José Orlandi, Jorge Jordán, Manuel Menéndez, L. L. Jacobs, John A. Esdale, C. Veiga, Leopoldo Feller, Stanley Rossier, W. Seliger, Chris Smith, Francisco Rabaglio y C. A. T. Riesco. Así como sociedades importadoras y exportadoras, industriales, ganaderas $\mathrm{u}$ otras, tales como Braun \& Blanchard, Metsen \& Refsgaard, Depolo \& hijo, Sociedad Ganadera Jente Grande, L. Meric y Co., Díaz, Contardi y Cía., Sociedad Anónima Ganadera y Comercial Sara Braun, Bonacic Hnos. \& Co., Townsend e hijo, Pisano \& Cía., Calcutta \& Fariña, G. \& C. Kreglinger, 


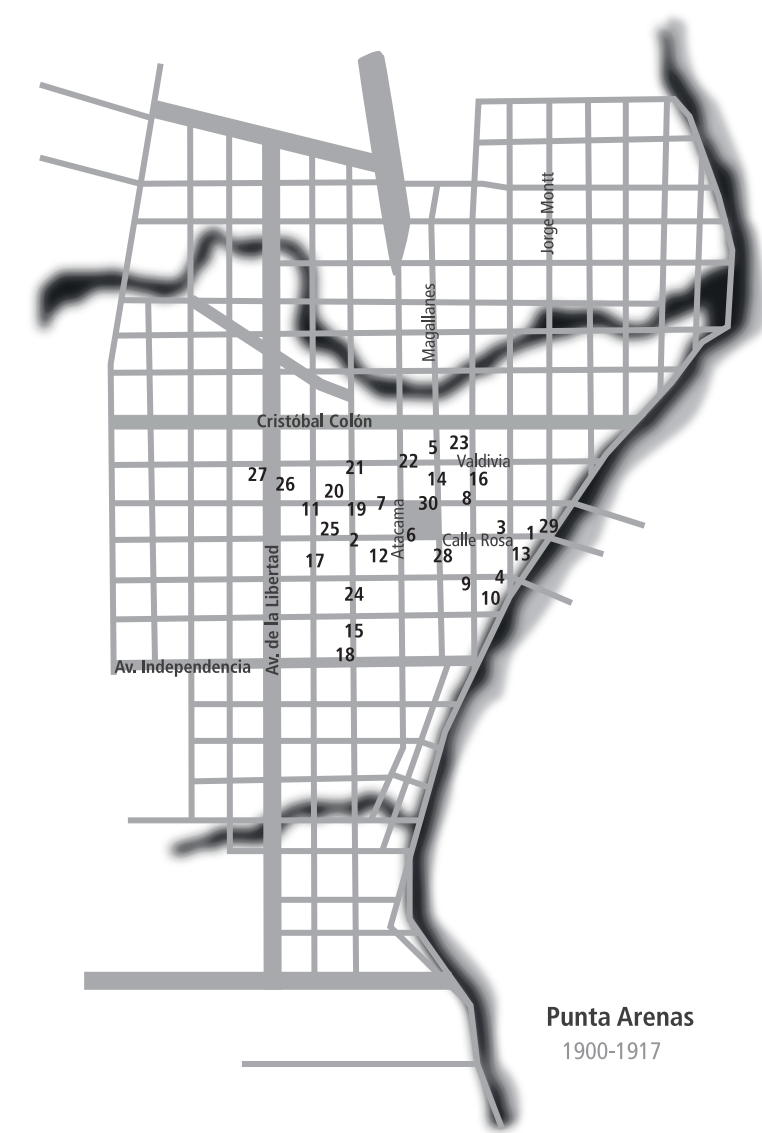

Stubbs \& Co., P. H. Lethaby \& Co., Arentsen Hnos., Sociedad Anónima Ganadera y Comercial Menéndez-Behety.

\section{Establecimientos}

Son principalmente cuatro los tipos de establecimientos que insertaron sus avisos en los periódicos de Punta Arenas a comienzos del siglo $\mathrm{XX}$ : Hoteles, bancos, colegios y establecimientos comerciales. En El Comercio del año 1900 anunciaron el Gran Hotel Chile, el Magallanes Hotel y los hoteles Paris, Bellevue, France y Kosmos; en 1914 hicieron lo propio el Royal, La Bolsa, Comercio, Imperial, The Queen's Hotel y The White Hotel, mientras que en 1917 sólo anunciaron cuatro de la ciudad -Hotel Imperial, Hotel France, Hotel Jogoslavija (ex La Bolsa) y Hotel Progreso- además de uno de Puerto Natales (Royal Hotel) y otro de Santa Cruz en Argentina (Bristol Hotel). Si bien en general se trataba de anuncios muy sencillos que prácticamente se limitaban a
Dentistas: Rogelio Sáez (1), F.E Davis (2), Dr. Mardones (3), Luis A. Vallejo (4)

Médicos: Domingo Solo Zaldívar (5), Carlos Exss (6), Florencio Middleton (7), B. González Lagos (8), Luis A. Aguirre (9), J. Pais (10), Dr. López (11), Jermán Vogel (12), Dr. Dodds (13), Munizaga Ossandón (14), Leonor López de Condell (15)

Matronas y otros: Emma Amó de T. (16), María J. Guzmán de Zenteno (17), pedicuro Herman Ullman (18)

Abogados: Ignacio Anguita Green (19), Luis. A. Valencia (20), Nibaldo Sanhueza (21), Francisco Salas de la T. (22), Esmaragdo Campaña (23), Ramón Luis Arriagada (24), Temistocles Urrutia Semir (25) Carpinteros y pintores: F. Cano Vásquez (26), Daniel Cáceres (27)

Agentes de aduana: Walter Dixon (28) y José Manuel Vega (29)

Ingeniero: H.C. Chetwood Aiken (30).

Fig. 3. Localización de profesionales en Punta Arenas 1900-1917.

recordar el nombre del establecimiento, algunos incluían detalles de sus servicios, como la calidad de su cocina y en especial sobre la variedad de vinos y licores. También descubrimos un par de casos que destacaban sus excelentes acomodaciones -que incluía caballerizas- y sus "precios módicos". Dichos datos permiten inferir las características de los pasajeros que recibían. Dentro de la hotelería más refinada, destaca especialmente la publicidad del Hotel France de R. Mounot, ubicado en la céntrica esquina de las calles Roca y O'Higgins que, además de los servicios esperables de un hotel, ofrecía sus dependencias para realizar banquetes de hasta cien personas. Un aviso en particular nos enseña la calidad de su cocina a raíz de una cena celebrada el 28 de octubre del año 1900 y que incluía una sopa, mayonesa de centolla, bocadillos de ostras, filete con arvejas, pollo à la broche, ensalada de berros, setas à la bordelaise, y helado de postre seguido de té o café. Por su parte, el hecho de que los avisos de los hoteles Magallanes y Bellevue estuvieran en inglés en un periódico como El Comercio insinúa 
que iban dirigido principalmente a miembros de esa colonia, concretamente a camp families and travellers. Por su parte, el tipo de viajeros que recibía el Hotel Paris también puede inferirse a partir de la información que proporciona su aviso, pues señalaba que dicho hotel era asimismo un "espléndido" restaurant donde podía comerse a cualquier hora, siendo su especialidad los tallarines, ravioles y polenta, esto es, comida menos selecta pero rica en calorías ${ }^{9}$.

En la medida en que fueron pasando los años, los nombres de los hoteles cambiaron y el France fue de los pocos que apareció durante todo el período estudiado. Hacia 1908, por ejemplo, anunciaron los hoteles Chileno, Comercio, Americano y Lion d'Or. Este último, recién inaugurado, ofrecía comida francesa e italiana para sus huéspedes como también comida a la carta. La calidad de la cocina, la variedad de licores y los precios "módicos" seguían siendo los argumentos más empleados en la mayoría de los anuncios de hoteles, a los que en ocasiones se agregaba una fórmula de identificación mayor hacia determinada colonia extranjera. Es el caso del Hotel Royal, que se limitaba en 1914 a calificarse como the English hotel in Punta Arenas, mientras que algunos años más tarde agregó el nombre del propietario y nuevo administrador, Ferdinand Garnier, haciendo gala de su experiencia en los mejores restaurantes de París. Pero hay dos argumentos que nos llaman especialmente la atención: La higiene y el buen servicio (prontitud y esmero). Si bien hacia mediados del siglo XX era posible hallar en la publicidad la técnica de ofrecer algo supuestamente obvio como una manera de plantear una duda acerca del competidor, en la época a la que hacemos referencia esa estrategia aún no era empleada. Esto hace pensar, por lo tanto, que aquello que se ofrecía - la higiene y trato esmerado- constituía una novedad o una exigencia que comenzaba a hacerse más común entre los viajeros y huéspedes. El Hotel Comercio, por ejemplo, ofrecía baños fríos, calientes y de ducha, incluso medicinales, y advertía que se hacía una desinfección previa a la vista del interesado ${ }^{10}$.

9 Esta información puede complementarse con el artículo de Martinic (2005).

10 Aviso del Hotel Comercio, Chile Austral, 11 de marzo de 1908.
Con respecto a los bancos, en 1900 insertaron regularmente sus anuncios el Banco de Tarapacá y Londres Ltd. y el Banco de Punta Arenas, mientras que en los años siguientes lo hicieron el Banco de Tarapacá y Argentina, el Banco de Londres y Río de La Plata, el Banco Anglo Sudamericano (ex Tarapacá y Argentina), el Banco El Hogar Chileno, el Banco de Punta Arenas y el Banco de Magallanes. En sus avisos normalmente entregaban información relevante tal como el capital con el que contaban, el monto de sus tasas de interés, los decretos supremos que regulaban su funcionamiento, localización de sus sucursales y los nombres de sus directores, presidentes y agentes.

En relación a los establecimientos educacionales, los avisos tendieron a informar acerca de la fecha de inicio del año, el horario, la tarifa y en algunos casos hasta los cursos que se impartían. En 1900, por ejemplo, el señor Walter Boll anunciaba que el Colegio Alemán del cual era su rector comenzaría a funcionar a partir del 15 de febrero en dicha ciudad en los salones del Club Alemán, en la calle General Koerner ${ }^{11}$. Incluía una tarifa (cinco pesos para los pupilos y tres para los pequeños asistentes al kindergarten) y llamaba a una pronta inscripción de los niños con la finalidad de organizar cuanto antes los cursos. Catorce años más tarde, hallamos dos anuncios de colegios, el del ya mencionado reverendo J. C. Carter y el que insertó en febrero Mrs. Giffen para anunciar que tenía la intención de abrir un colegio privado en su casa. En este último anuncio se incluyó información que puede resultar de gran relevancia para conocer algo acerca del funcionamiento de instituciones de esa naturaleza, ya que comunicaba que abriría el 3 de marzo, que los niños de "kindergarten" podrían estar de 9 a 11:30 todos los días, a excepción de los sábados que recibirían clases de pintura y dibujo de 10 a 12 horas, y de danza desde las 2 a las 3 de la tarde. Por un par de avisos publicados tres años más tarde en The Magellan Times del Mrs. Giffen's English School para niños y niñas en la calle Chiloé de Punta Arenas ${ }^{12}$, nos enteramos de que ya no se localizaba en su casa, por lo que presumimos que su proyecto educativo se estaba

11 El Comercio, 31 de octubre de 1900.

12 Dicho colegio fue fundado precisamente el año 1914 y funcionó hasta el 1922, véase Edmundson (2009, p. 195). 
consolidando. También se insertó entonces el anuncio del Cricklewood School para señoritas en la calle Pringles de Buenos Aires, lo que nos hace suponer que ese periódico podía llegar a circular por la capital argentina o, quizá, que algunas familias de Punta Arenas decidían enviar a sus hijas a aquella ciudad para recibir su educación. Tal como un anuncio proporciona información útil para el historiador, ciertos "silencios" también prestan una función. La ausencia del aviso del reverendo Carter en ese mismo año 1917, por ejemplo, permite preguntarnos si su colegio estaba lo suficientemente afianzado de manera que no consideraba necesario recurrir a la publicidad o, por el contrario, había desaparecido. Es inevitable recordar su cambio de estrategia publicitaria tres años antes cuando, como ya señalamos, a mediados de año utilizó técnicas más "agresivas" y con evidentes énfasis persuasivos orientados a convencer a los ingleses residentes en la ciudad y su entorno acerca de que su colegio conservaría a sus hijos como "auténticos británicos".

Pero no hay duda que en lo que a establecimientos se refiere, los anuncios publicitarios de la prensa se constituyen en una rica cantera para descubrir la oferta de locales comerciales con que contaban los puntarenenses de comienzos del siglo XX. Es cierto que las matrículas de patentes y algunos anuarios ofrecen información más detallada acerca de todos los locales de una ciudad y no sólo de los que recurren a la publicidad. Así, si en el Anuario Prado Martínez de 1905 aparecen treinta y tres casas importadoras y veintidós tiendas de mercaderías surtidas en Punta Arenas, constatamos que apenas un tercio insertó avisos en la prensa (Prado Martínez, 1905, p. 203). Sin embargo, dicho anuario no registra la dirección de los establecimientos y sólo consigna los nombres de los propietarios, de manera que no es posible ubicar los locales que llevaban algún nombre de fantasía. Los avisos publicitarios, en cambio, si bien constituyen sólo una parte del comercio de la ciudad, proporcionan valiosa información relativa al nombre del establecimiento, su localización, los productos en oferta y en ocasiones incluso sus precios y otros detalles que hacen posible entregar un contexto social y funcional del bien de consumo promocionado.

En términos generales, la publicidad ofrece un escenario ocupado por un cierto número de locales medianamente especializados -lo que se desprende de sus denominaciones y en ocasiones por los detalles acerca de los productos o servicios en oferta- junto a un importante predominio de casas importadoras de diferentes tamaños. No todas ellas tenían aun claramente separadas la fabricación o manufactura de la venta, como es el caso de hojalaterías, herrerías, tonelerías, sastrerías, cervecerías y talabarterías. Dentro de los locales más especializados, podemos identificar las droguerías y boticas, librerías, armerías, paqueterías, relojerías y joyerías, panadería, confiterías y peleterías. En cuanto a los establecimientos que ofrecían comida y bebidas, además de los hoteles, había algunos restaurantes, cafés, bares, cantinas y "recreos". También hallamos cierta distinción entre algunos locales de venta de productos similares para abastecer a las familias, tales como recovas, provisiones, emporios, almacenes y bodegas. Los avisos más destacados y numerosos eran aquellos que ofrecían un amplio surtido de artículos y que recibían la denominación de "tiendas", "casas" o simplemente "importadoras". Se trataba de establecimientos de dimensiones variables que actuaban no sólo como vendedores al por menor, sino que además como intermediarios, ya que hacían las veces de agentes de importación y, en ocasiones, también de exportación. Los casos más emblemáticos son los de sociedades que teniendo diversas funciones, insertaban diferentes avisos en el mismo ejemplar del periódico, como Braun \& Blanchard: en 1900 era una sociedad dedicada al comercio marítimo de manera que ofrecía pasajes y fletes a Puerto Porvenir (miércoles y sábado), a Cabo Negro, isla Isabel, Pecket Harbour, San Gregorio, Punta Espora y Punta Delgada (quincenalmente), Río Gallegos, Santa Cruz y San Julián (mensualmente). Se autocalificaba de "agentes, consignatarios y armadores de buques"13. Pero, también se dedicaba a las ventas en su "almacén general" de una amplia variedad de productos que incluía madera, planchas y barras de fierro, alambre, cocinas, estufas $y$ pinturas 
a conservas, cigarrillos y "provisiones de todas clases". Además, decía ser representante de varias marcas europeas, tales como los chocolates Menier, el tabaco Mackill Laidlaw, el coñac Martell, polvos desinfectantes Cooper, y agentes de aseguradoras como New York, Unión, Lancashire y Manheim. Catorce años más tarde, seguía con el negocio importador y los servicios marítimos, y dentro de sus ofertas también aparecían desde vestuario y calzado hasta maquinarias y automóviles.

Además de casas importadoras grandes, como la mencionada Braun \& Blanchard y también Stubenrauch \& Co., había otras más pequeñas, como la casa importadora y exportadora de José Pasinovich, la de José Menéndez, o la de Jorge Matetich, por mencionar algunas. Según se constata en los avisos publicitarios, si bien la mayor parte de estas casas ofrecía una amplia gama de productos, tendían a especializarse o concentrarse en determinadas ramas. No deja de ser elocuente, en tal sentido, el aviso de la Casa Inglesa de L. L. Jacobs que además de dar un listado de artículos de vestir con sus respectivos precios, avisó con cierta insistencia que no hay licores ni abarrotes solamente ropa hecha, zapatería y tienda ${ }^{14}$. Esto podría significar que los puntarenenses estaban habituados al local de "mercaderías surtidas" en el que podía hallarse casi de todo, modelo de negocio que suele darse en ciudades cuyos mercados aún son pequeños, pese a que ya la ciudad empezaba a demostrar ciertos grados de especialización. Así, para artículos de vestuario había que acudir donde L. L. Jacobs, A. Hunter y Cía., José Menéndez (y luego a sus sucesores Alfonso y Julio Menéndez), Jorge Schultz y Cía., Frey \& Elkan, al Baratillo Centenario de Dougnac y Cía. Para muebles, papeles pintados y obras de arte para decorar el hogar estaban La Económica de Francisco Rabaglio, Jorge Matetich, À la Ciudad de Pekín y À la Ville de Chicago; y si se buscaban artículos para la construcción o herramientas y maquinarias, estaban Braun \& Blanchard, además de Hardcastle y Co., entre otros.

Al igual que lo que hicimos para el caso de los profesionales, localizamos los establecimientos comerciales sobre un plano de la ciudad. Este ejercicio nos parece de interés en especial para la historia urbana, pero reviste dos dificultades.
La primera es que no todos los anuncios detallan su dirección pues, de hecho, normalmente los más conocidos y relevantes no lo hacían, de manera que quedan fuera de la muestra algunos lugares emblemáticos de la ciudad. La segunda es que, dado que las numeraciones de las calles han cambiado, no siempre es posible ubicarlos con exactitud, por lo cual optamos por localizar aquellos que señalan una esquina o referencias más precisas tales como "junto a", "frente a", u otras similares. Escogiendo los anuncios que cumplían con lo anterior confeccionamos dos planos para los establecimientos comerciales y algunos hoteles en períodos diferentes correspondientes a los años 1900-1908 y 19121917 respectivamente (Figs. 4 y 5).

Estos planos comerciales de la ciudad confirman la tendencia común de los centros urbanos, a saber, que el comercio comienza a concentrarse en el corazón de la misma para luego irse extendiendo hacia la periferia. En este caso, y pese a que la muestra es pequeña, se observa dicha concentración en torno a la plaza Muñoz Gamero, su posterior expansión en todo su entorno, aunque en especial hacia el Estrecho, siendo las calles Valdivia, Atacama y especialmente Roca, las que tenían mayor presencia comercial.

Hasta la primera década del siglo XX fueron escasos los locales reconocibles por un nombre de fantasía que actuara como marca, sino que se identificaban con los de las sociedades propietarias. Es el caso de Rothenburg \& Petersen, Montaldo, Gerdtzen \& Cía., Thiessen \& Cía., P. H. Lethaby \& Co., Detaille, Henkes y Co., Pisano \& Foggie, William Cooper \& Nephews, Stubbs \& Co., Mayer Braun, Arentsen Hermanos y Cía., Michel Rooze \& Co., Braun \& Blanchard (Fig. 6), Stubenrauch \& Co., Díaz, Contardi y Cía., Wood Brothers. Otros se identificaban con el nombre de su propietario (L. G. Dobrée, Leopoldo Feller, Francisco Rabaglio, Ernest Manns, C. Veiga, Frank H. Townsend) y en The Magellan Times lo hacían con la fórmula inglesa para "donde X", esto es, Riesco's y Arentsen's. Dentro de los nombres de fantasía con el que ya se identificaban algunos establecimientos en sus avisos, se encuentran en 1900 las peluquerías Francesa y La Marina, Recreos Miraflores y Miramar, Café Sandy Point, Bar Angloamericano, Farmacia y droguería

14 Aviso de L. L. Jacobs, El Comercio, 16 de diciembre de 1900. 


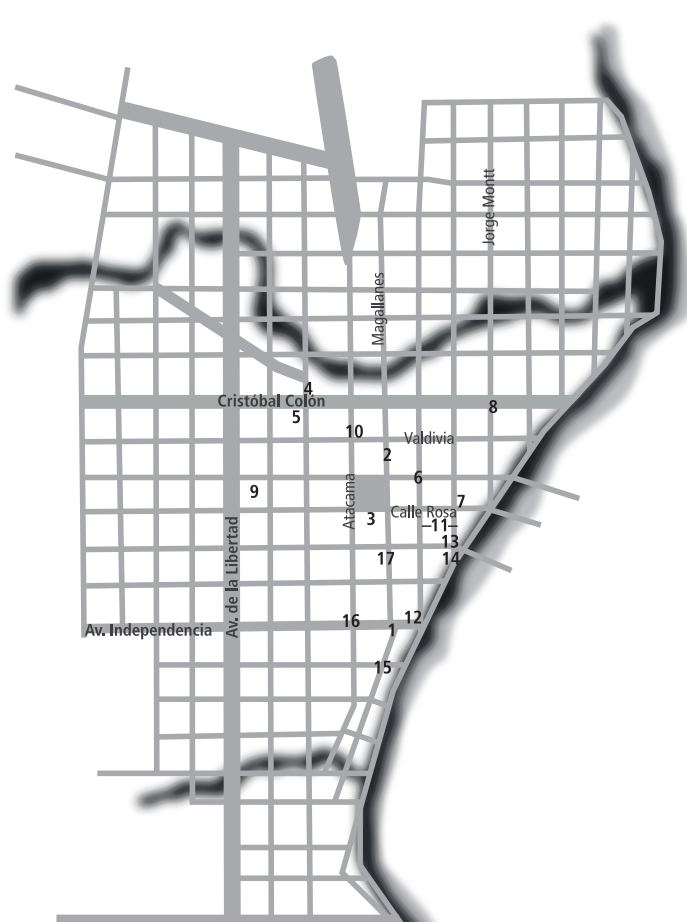

1. Rothenburg \& Petersen

2. L.G. Dobrée

3. Droguería Francesa

4. Almacén de Contardi

5. Restaurant de G. Leguas

6. Hotel Paris

7. Hotel de France

8. Panadería Universal

9. Á la Ville de Chicago

10. Almacén El Porvenir

11. Montaldo, Gerdtzen \& Cía., Gran Hotel Chile,

Thiessen \& Cía., Sastrería Moderna, Librería Hugo,

Peluquería Francesa, Relojería y joyería Inglesa, Café

Sandy Point, Farmacia y droguería Magallanes, Hotel

Lion d'Or, Emporio fotográfico de C. Veiga

12. Carpintería La Independencia

13. Provisiones Jorge Jordán

14. Al Zorro

15. Hardcastle y Cía.

16. Paquetería de E. Carreño

17. Stubenrauch y Co.

Punta Arenas

1900-1908

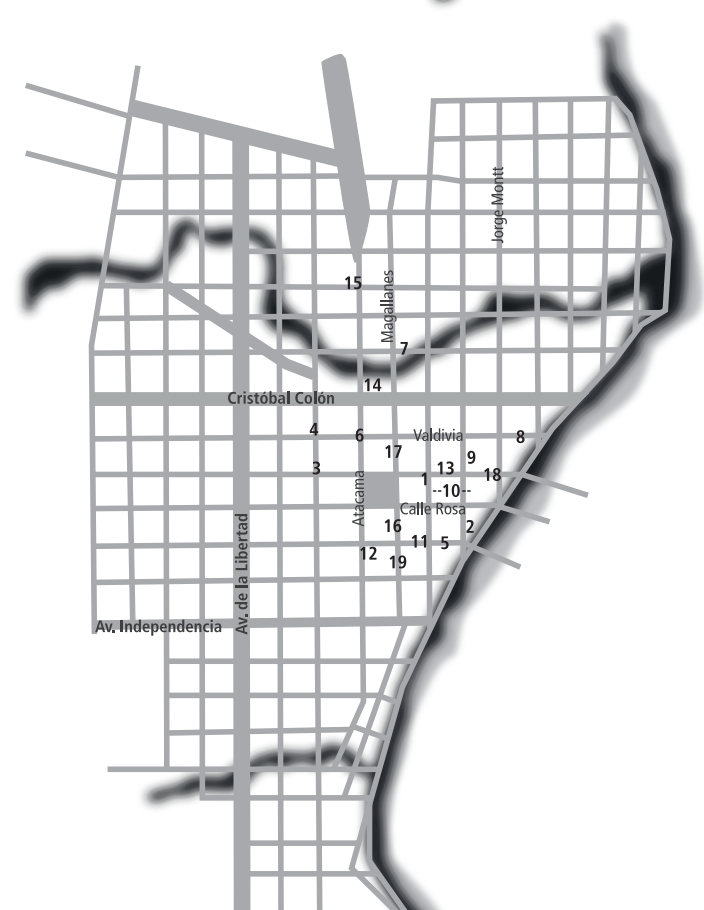

Fig. 4. Localización de establecimientos comerciales de Punta Arenas en 1900-1908.
1. Skirving \& Co.

2. Peletería El Zorro

3. P.H. Lethaby \& Co.

4. Bodega San Luis

5. Relojería y joyería Waltham

6. El Arco Iris de Alberto Margas

7. Mayer Braun

8. Taller Nacional

9. Arentsen Hnos. \& Cía.

10. Tienda de Kodak de C. Veiga, Mueblería de Francisco Rabaglio, Goeminne \& Blaya, Ferretería de N. Sorecich, Dougnac \& Cía., Botica Alemana, Jorge Matetich, Fotografía Pacheco

11. W. Seliger

12. Wood Brothers

13. Hotel Progreso

14. Gran Ferretería de Bucksbaum

15. Hotel Helvetia

16. Detaille Henkes \& Cía.

17. Riesco Lethaby \& Cía.

18. La Nueva Recova

19. Stubenrauch y Cía. 


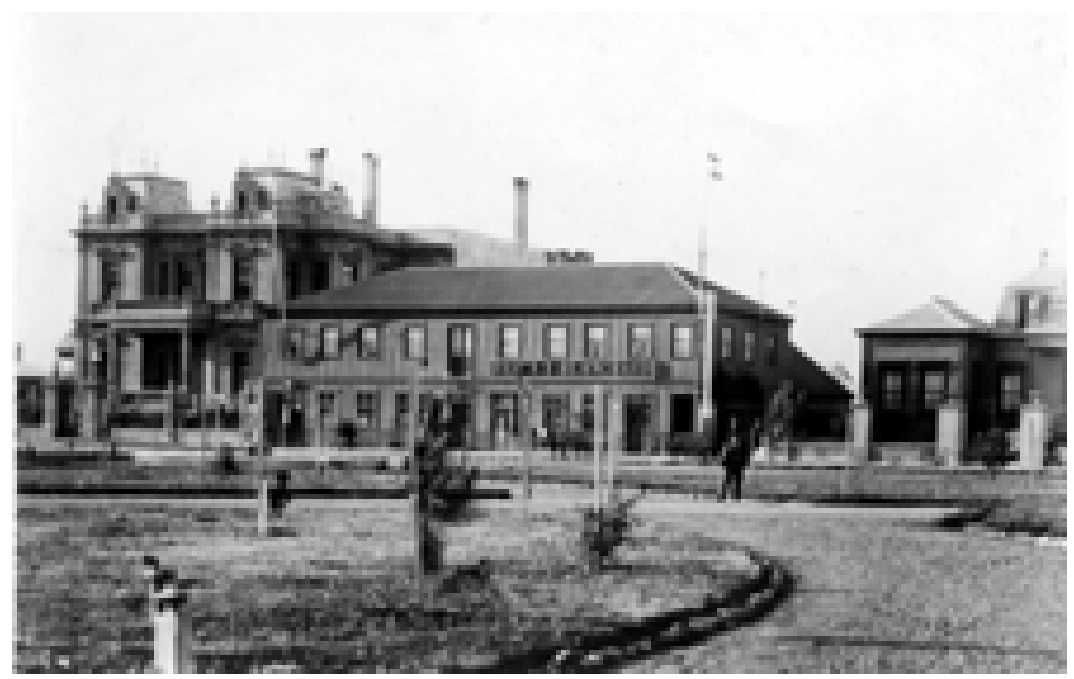

Fig. 6. Braun \& Blanchard ofrecía servicios marítimos de envíos, bodegaje y seguros, además de disponer de un gran surtido de productos para la venta al por menor (Archivo Universidad de Magallanes).

Magallanes y Francesa, Sastrería Moderna, Casa Francesa, Librería Hugo, Almacén Central y El Porvenir, relojería y joyería Inglesa, Cigarrería La Corona. Hacia 1912-1917 la tienda de Francisco Rabaglio ya era conocida como La Económica, la peletería de G. M. Grossi llevaba el nombre de El Zorro y el establecimiento de Dougnac y Cía. se denominaba Baratillo Centenario. También se identificaban con un nombre el Taller Nacional, el cinema o sala Lilley, El Arco Iris, Barraca Centenario, The Magallanes Motor Garage, La Puntarenense y Taller Minerva, mientras que Auto Garage Central de L. Meric \& Co. y Casa Inglesa de L. L. Jacobs, estaban en una etapa de transición que combinaba el nombre de fantasía con el de la sociedad propietaria.

\section{Productos}

A través de la identificación y posterior cuantificación de las ofertas presentes en los avisos se puede tener el detalle de los bienes y servicios que recibían los lectores de los periódicos estudiados. Debido a que entonces los anuncios se repetían casi invariablemente año a año, se escogieron muestras pequeñas consistentes en dos ejemplares por cada año consultado: 26 y 28 de octubre de 1900 (El Comercio), 12 y 14 de febrero de 1907 (El Comercio), 1 y 2 de octubre de
1912 (La Unión), 4 y 18 de febrero de 1914 (The Magellan Times) y los días 6 y 13 de septiembre de 1917 (The Magellan Times). Tomando en cuenta el promedio del total de avisos publicados en cada muestra - 108 para 1900, 79 para 1907, 86 para 1912, 48 para 1914 y 74 para 1917- se advierte una tendencia a la baja en los avisos de servicios en relación al total, que contrasta con la tendencia inversa de aquellos que ofrecían bienes de consumo. Así, por ejemplo, si el $62 \%$ de los anuncios de El Comercio en 1900 era de servicios, para The Magellan Times en 1917 dicho sector sÓlo representaba el 39\% del total de anuncios. Con respecto a los servicios profesionales, la oferta más abundante la hallamos en 1900: dos cocineras, un agente comisionista, dos dentistas, un profesor de inglés y francés, cuatro médicos, tres abogados, dos ingenieros y una matrona. Ello podría tener distintas explicaciones que no es del caso estudiar aquí, pero que podrían sugerir cambios en el mercado laboral o la política del periódico, ya que, si vemos las cosas en detalle, la gran diferencia se da en que los particulares insertan menos avisos ofreciendo sus servicios en la medida en que pasan los años. Dentro de los servicios, es interesante constatar que, si los anuncios de bancos y establecimientos educacionales representaron entre el $2 \%$ y $4 \%$ del total de anuncios, los hoteles y compañías aseguradoras alcanzaron entre el 
$5 \%$ y el $9 \%$ aproximadamente. En cuanto a las últimas, se ofrecieron especialmente seguros de vida y contra incendios por parte de la National Assurance Co. of Ireland, Union Assurance Society de Londres, La Manchester, New York, Law Union \& Crown, Unión Comercial y The Sun Life Assurance Company of Canada, hacia el año 1900 mientras que en 1917 insertaron avisos "La Austral", que cubría riesgos de incendio y marítimos, la Phoenix Fire Assurance Company Limited, la Norwich Union Fire Insurance \& Co. y Norwich Union Life Assurance Society, además de The Sun Life Assurance Company of Canada.

Dado que la mayor parte de la publicidad era de establecimientos comerciales que buscaban promocionar sus productos, dichos anuncios fueron trabajados con una metodología específica. Así, después de cuantificar los productos identificados en los mismos y clasificarlos de acuerdo a su naturaleza, se registraron los resultados en tres tablas. En la primera (Tabla 1) fueron incluidos aquellos productos destinados al hogar y a la familia en general, en la segunda (Tabla 2) los que ofrecían artículos de uso personal $y$, por último, la tercera (Tabla 3) agrupó a todos aquellos bienes destinados a la construcción y a las actividades industriales, agrícolas, forestales y ganaderas. Con respecto a los productos destinados a la familia, se constata que aparecen escasos productos alimenticios, los que durante todo el período se limitaron a papas y legumbres frescas y secas o productos afines, y más tarde también papas holandesas, cebollas de Lisboa, harina chilena y argentina, queso parmesano, aceitunas negras de Grecia, conservas y fideos italianos ${ }^{15}$. La carnicería de Ladouch y Co. ofrecía fiambres, verduras, aves, carne y "animales en pie"; en la Chanchería Alemana de R. Beherens había toda clase de embutidos y la Frutería La Estrella Tricolor de J. Esteban Guerrero contaba con frutas, cereales, chichas, licores y otros productos "para familias"16. También hallamos anuncios de aguas minerales (nacionales, húngaras y bohemias) que se ofrecían en almacenes, pero también en boticas, bebidas alcohólicas, como

15 Avisos de Ballester \& Co. En El Comercio, 13 de febrero de 1907, de La Nueva Recova en La Unión, 1 de octubre de 1912 . cerveza, vinos (nacionales, italianos, franceses y "dálmatos") y whisky. Este último producto fue, de hecho, uno de los más presentes en la prensa dirigida a la colonia británica. El café y el té aparecen escasamente individualizados, probablemente porque se compraba en los almacenes que ponían sus avisos sin detallar sus productos, y sólo aparecen marcas como café La Brasileña y El Globo y las de té Demonio, Santa Rosa y Azalea. Cabe tener en consideración que en esta época uno de los productos relevantes de la oferta existente en los periódicos capitalinos fue el té, hasta el punto de que sus anuncios son uno de los mejores ejemplos de competencia publicitaria que hemos detectado en los comienzos del siglo XX en diarios como El Ferrocarril y El Mercurio de Santiago. En Punta Arenas, en cambio, los anuncios de té fueron escasos y poco llamativos, lo que no deja de llamar la atención si se considera la natural asociación que se hace de dicha bebida con la cultura británica, tan presente en esta ciudad austral. Para la decoración del hogar la oferta fue algo escasa, aunque tendió a ampliarse al avanzar los años, y consistió en pintura, cortinas, hules para pisos y mesas, colchas de piqué, alfombras, loza y en especial muebles y papeles murales. Y en relación con adelantos tecnológicos que dan cuenta de la llegada de la modernidad a Punta Arenas, es a partir del año 1912 que se publican avisos de automóviles, coches y motocicletas, además de gramófonos, máquinas fotográficas y de escribir.

Con respecto a los artículos de uso personal, se insertaron avisos de moda femenina e infantil, además de masculina; claro que en una proporción muy inferior a la que en dicha época podía advertirse en los mencionados periódicos capitalinos. Tales anuncios hacen posible conocer las piezas de vestir que podían comprarse entonces en Punta Arenas, en una época en que aún no estaba extendida la compra de ropa hecha pues muchas piezas de vestir se hacían a la medida por sastres, modistas y costureras (Dussaillant, 2011. op. cit.). De hecho, los avisos puntarenenses ratifican la evolución del mercado

16 Aviso de carnicería en La Unión, 1 de octubre de 1912. Y de chanchería y la frutería en Eco de la Guerra, 19 de octubre de 1914. 
Tabla 1. Número promedio de avisos relativos a productos para el hogar y la familia. Elaborada por la autora.

\begin{tabular}{|c|c|c|c|c|c|}
\hline Artículos & 1900 & 1907 & 1912 & 1914 & 1917 \\
\hline Automóviles, coches, berlinas & - & - & 1 & 2 & 6 \\
\hline Bicicletas, motocicletas & 1 & - & - & - & 1 \\
\hline Pintura, papel mural, alfombras, cortinas, muebles & 2 & 3 & 5 & 1,5 & 2 \\
\hline Cámaras fotográficas, máquina de escribir, gramófonos & - & - & 2 & 3 & 2 \\
\hline Máquinas de coser & - & 2 & - & - & - \\
\hline Telas & 1 & 1 & - & - & - \\
\hline Artículos para limpieza de ropa & - & - & - & - & 1 \\
\hline Agua & - & 1 & 1 & - & 2 \\
\hline Alcohol (vino, whisky, destilados en general) & 7 & 7 & 6 & 3 & 5 \\
\hline Café & - & - & - & 2 & 1,5 \\
\hline Té & - & - & 2 & - & - \\
\hline Chocolate, golosinas & - & & 1 & 1 & 1 \\
\hline Frutos del país & 3 & 1 & 3 & 2 & - \\
\hline Tabaco/cigarrillos & 2 & 2 & 1 & 1 & - \\
\hline Cerveza & 3 & 2 & 2 & - & - \\
\hline Leche & - & 1 & - & - & - \\
\hline Armas & - & 2 & - & - & - \\
\hline Loza/cubiertos & 1 & 2 & - & - & - \\
\hline Libros & 1 & - & - & 1 & 1 \\
\hline Instrumentos musicales (piano) & - & 1 & - & 1 & 1 \\
\hline
\end{tabular}

de la ropa hecha que comenzó primero con trajes para caballeros y niños y más tarde para mujeres, pues la moda femenina fue menos adaptable a tallas estandarizadas hasta la Primera Guerra. Así, dentro del vestuario femenino en 1900 sólo se ofrecía "hechuras a precios convencionales" de trajes sastre y de amazonas para señoras en la Sastrería Moderna de A. Hieroltz, pero no de ropa hecha. En cambio, para los señores la misma sastrería ofrecía pantalones, ternos, chalecos de piqué blanco para "soirés" y telas para fracs y smokings. El mismo año L. L. Jacobs tenía ternos, pantalones, zapatos, botas, camisas, alpargatas, medias, sombreros, camisetas, calzoncillos y gorras para caballeros, además de artículos para señoras y niños (sin especificar) y "ropa para trabajadores a precios bajísimos"17. Por su parte, Thiessen y Cía. ofrecía un "gran surtido de ropa hecha para caballeros, jóvenes y niños" que incluía sobretodos de media estación, medias de lana, ropa interior, mientras que para señoras había refajos de lana y de seda, jerseys y blusas de lana, forros para vestidos y cariñosas de lana "alta novedad". Esta última prenda no la habíamos hallado en ninguna oferta de ropa en estudios previos acerca del tema y parece ser un nombre muy local, probablemente como una traducción del inglés o francés y, por su nombre y el hecho de que fuera de lana suponemos que se trataba de una prenda de abrigo. Siete años más tarde la oferta en vestuario era muy similar, pues sólo aparecían "trajes para señoras" y "cortes de vestidos" y recién hacia 1914 se advierte un surtido mayor de prendas para el vestir femenino tales como vestidos de baile, batas, trajes a medida, lencería, cortes de seda, blusas "a la última", camisas, telas para vestidos, zapatos y botas, todo en L. L. Jacobs. Con respecto a los niños, la misma tienda ofrecía en 1912 trajes de marinero con pantalón largo, además 
Tabla 2. Número promedio de avisos de oferta de productos de uso personal. Elaborada por la autora.

\begin{tabular}{lccccc}
\hline Artículos & 1900 & 1907 & 1912 & 1914 & 1917 \\
\hline Vestuario femenino & 3 & 1 & 2 & 3 & 3 \\
Vestuario masculino & 3 & 1 & 2 & 1,5 & 3 \\
Vestuario infantil & 2 & 1 & 2 & 2,5 & 2 \\
Calzado en general & 1 & 1 & 1 & 3 & 2,5 \\
Sombreros, paraguas, bastones y otros accesorios & 3 & 1 & - & - & 1 \\
Joyas / relojes & 3 & 1 & - & - & - \\
Medicamentos & 2 & 1 & 1 & - & 1 \\
Higiene y cosmética & 2 & - & 2 & - & 1 \\
\hline
\end{tabular}

de vestones "cruzado o derecho" y, lo más interesante, recibían órdenes para confecciones en Londres ${ }^{18}$. Dos años más tarde el local de Riesco contaba con abrigos, medias, calcetines, zapatillas de fieltro ${ }^{19}$ y el establecimiento de Frey \& Elkan con una "especialidad en trajes para niños" 20 . En el mismo local de Riesco, los caballeros podían abastecerse de camisas, cuellos, ropa interior, calcetines, corbatas, gorras, polainas, abrigos, trajes, impermeables y guantes; mientras que Stubbs \& Co. les ofrecía impermeables y abrigos "Rexine", pantalones de montar, paraguas y bastones. En la tienda de Ernest Manns se vendían camisas, sombreros y calcetines en general (no se especifica, sólo se señala para señoras, caballeros y niños), además de un amplio surtido de bordados suizos; en tanto que Stubbs \& Co., también en términos generales, ofrecía una amplia variedad de ropa interior en seda, lana y algodón para señoras y caballeros $^{21}$. Por otro lado estaba la opción de mandar a confeccionar las prendas de vestir en sastrerías como la alemana de Rodolfo Kauer o la de Winter \& hijos ${ }^{22}$. Tres años más tarde, la Casa Inglesa de L. L. Jacobs promocionaba para los caballeros tweeds escoceses (Harris) e irlandeses (Donegal, Ardara y Connemara), además de trajes, corbatas, chaquetas deportivas, cuellos y camisas; mientras que en Braun \& Blanchard encontraban impermeables, botas de

18 Aviso de Casa Inglesa en La Unión de 1 de octubre de 1912.

19 The Magellan Times, 4 de febrero de 1914.

20 Eco de la Guerra, 19 de octubre de 1914.

21 The Magellan Times, 18 de febrero de 1914.

22 Eco de la Guerra, 19 de octubre de 1914.

23 Los datos sobre El Mercurio fueron extraídos de Dussaillant goma y trajes deportivos. Las mujeres y niños, en cambio, solo recibieron avisos muy generales de zapatos y botines, y de "toda clase de ropa" sin mayores especificaciones.

Pero no hay duda de que lo que realmente llama la atención es la falta de avisos de medicamentos y de productos cosméticos y de higiene personal, que aún cubrían muchas páginas de los mencionados periódicos capitalinos de entonces. Los ungüentos, elíxires, jarabes, pastillas y otros productos similares que en El Mercurio de Valparaíso entre 1900 y 1920 representaron entre el $27,5 \%$ y el $24,1 \%$ del total de anuncios, en la prensa magallánica estudiada representa no más del $0,5 \%^{23}$. Es cierto que la edad de oro de los curalotodos ingleses y especialmente franceses ya comenzaba a declinar $y$, de hecho, en un aviso publicado en El Magallanes de diciembre de 1893 la farmacia y droguería del mismo nombre ofrecía precisamente algunos de los más reconocidos: aguas minerales de Vichy, Hunyadi Janos, Apolinaris y Karlsbad, además de las píldoras purgantes de Brandreth, Bristol y las célebres píldoras de Holloway ${ }^{24}$. Sin embargo, en la prensa revisada para el período 1900-1917 no aparece identificado ninguno de ellos, y sólo se menciona una muy general alusión a "drogas y específicos y aguas minerales de Droguería y botica Francesa en 1907 y $1912^{25}$ y el Elixir Saiz de Cárlos que promocionaba la Botica y droguería Alemana

(1993, op. cit. pp. 114 y 115) mientras que el de la prensa magallánica se calculó para este estudio contando los anuncios de este tipo de productos en relación al total.

24 El precursor de "El Magallanes", 25 de diciembre de 1893.

25 Avisos de El Comercio, 13 de febrero de 1907 y de La Unión, 1 de octubre de 1912 respectivamente. 
de Neumann. Con respecto a los productos de higiene y belleza, sólo se insertaron avisos del champú Secreto del Oriente y la pasta dental Royal Vinolia ${ }^{26}$.

Por último, en las categorías orientadas al ámbito laboral y productivo, es fácil constatar la supremacía de la actividad lanera de la zona. Predominaban las maquinarias para trasquilar y prensar lana, además de los polvos y líquidos desinfectantes y los líquidos para marcar ovejas. Más aún, los anuncios más destacados en cuanto a técnicas para llamar la atención y para persuadir al lector, fueron precisamente estos últimos, en especial los de de marca Cooper. Una incipiente lucha publicitaria demuestra la relevancia que tenía ese producto para dicha industria. Orientados a la construcción y a las actividades propias de las haciendas se especificaban productos tales como tubos de acero, tuberías en general, planchas y tejas de asbestos para el tejado que decían tener la particularidad de ser resistentes al fuego, revestimientos y muros exteriores en diferentes tamaños, espesores y colores, también cemento de Portland, instalaciones para aserraderos y sierras especiales para cortar leña. Hacia mediados del período estudiado también aparecieron tanques para gasolina, lámparas, vidrios para ventanas, masilla, marcos para cuadros, molduras nacionales y extranjeras, patas esclopeadas para mesas y marquesas, madera de laurel para pisos, forro y cielo, también aceite de linaza, trementina, pinturas y barnices, papeles murales, alambre, fierro galvanizado, carbón, aceite y grasa para motores, cemento inglés, arados, segadoras, calderas y para los "viajeros", sillas de montar inglesas, arneses, baúles y maletas.

La marca

La presencia de la marca resulta una suerte de indicador del desarrollo de la industria, el comercio y de la actividad publicitaria. Esto porque en un contexto en el que la producción se ha ido separando de la comercialización, el consumidor final de un producto ya no tiene una relación directa con el productor del mismo, de manera que la "marca" se constituye en un elemento esencial que conecta a ambos a través de la intermediación del comerciante. Los productos que aparecen promocionados en los avisos bajo el nombre de una marca, presuponen normalmente algo más complejo, que tiene que ver con que se trata de un producto individualizado, envasado, rotulado y ya no como una mera venta a granel. Es decir, la sola existencia de la marca indica que el consumidor comienza a escoger un nombre y los valores a él asociados, y no sólo un producto. Se trata, pues, de una etapa de mayor desarrollo dentro de la evolución de las prácticas de consumo que sigue a la compra a granel la que, al ofrecer la mercadería en grandes sacos o barriles abiertos, no exigía ni permitía mayores miramientos estéticos en el local, sino que sólo se trataba de un orden funcional. La producción masiva combinada con la venta al por menor se tradujo en la necesidad de envasar y marcar individualmente el producto, lo que fue señal de un cambio muy relevante de mentalidad. Esto porque los productores dejaron de considerar al tendero como su cliente, y pusieron la mirada sobre el consumidor final como su auténtico objetivo (Eguizábal, 1998, p. 163), lo que finalmente se tradujo en una mayor preocupación por parte del

Tabla 3. Número promedio de avisos de oferta de productos para área productiva. Elaborada por la autora.

\begin{tabular}{|c|c|c|c|c|c|}
\hline Artículos y servicios & 1900 & 1907 & 1912 & 1914 & 1917 \\
\hline Podadoras, esquiladoras, prensas para lana y herramientas afines & 1 & 1 & - & 3 & 2 \\
\hline Desinfectantes ovejas y lana & 3 & 2 & - & 4 & 5 \\
\hline Combustibles y aceite para máquinas, servicios y reparaciones & - & - & - & 1 & 6 \\
\hline Artículos para aserraderos & 2 & 3 & 1 & 1 & 2 \\
\hline Sillas de montar y artículos afines & - & - & - & 1 & 2 \\
\hline Artículos para agricultura & 2 & - & - & - & 1 \\
\hline Artículos para construcción; fierros, alambre & 3 & 1 & 3 & - & - \\
\hline
\end{tabular}


comerciante de proporcionar un ambiente grato a su clientela. En otras palabras, la mayor o menor presencia de marcas entre los avisos publicitarios no sólo habla de productos individualizados, sino también del grado de evolución experimentado por los puntos de venta.

De la mano de la marca y la publicidad, el comercio poco a poco fue invadiendo las calles de signos que pasaron a constituirse en nuevas maneras de conocer y reconocer la ciudad, hasta el punto de que sus habitantes solían utilizar el nombre de un establecimiento comercial como referente más que el nombre de una calle o la numeración de un determinado local. Esto se advierte en algunos avisos de la prensa estudiada, como el de Rodolfo Gerli que ofrecía tumbas y cruces de mármol y granito en su local ubicado "junto a los Sres. Stubbs \& Co.", el de la Paquetería Francesa que se hallaba "al lado del Sporman Bar", La Hojalatería y Herrería de Jaime y Jordana ubicada en calle Aconcagua al lado de la Pastelería Colonial ${ }^{27}$. El letrero adosado al muro con el nombre del establecimiento se transformó crecientemente en un identificador no sólo del establecimiento en sí mismo y como tal de un referente en la trama urbana, sino también de información relevante para el habitante urbano en general, y el consumidor en particular. Elocuente es al respecto el aviso de la Tintorería Internacional que además de entregar la dirección exacta, decía:

\section{AVISO}

\section{-Señora, qué busca Usted?}

-Bueno caballero, la Tintorería Internacional... yo, también... aquí está: calle Ñuble 910 (esquina Valdivia). Fijese en el letrero: limpia, desenmancha, plancha, compone, tiñe, etc... Entremos... pase adelante. Sra.: Nuble 910. ${ }^{28}$

La revisión de los avisos publicitarios de El Magallanes de finales del siglo XIX y El Comercio de comienzos del XX, demuestra que los establecimientos comerciales -exceptuando los hoteles- en general seguían identificándose con el nombre de sus dueños, ya fueran individuos o sociedades. Esto en parte debido a que se trataba en verdad de firmas que aún no tenían del todo

27 The Magellan Times, 14 de diciembre de 1921. Literalmente señala: "Calle Bóries 659 (next to Messrs. separados sus roles de importación y de ventas, e incluso, algunas de ellas además actuaban como representantes de compañías extranjeras, entre otras funciones. Es el caso de Heede \& Glimmann, Stubenrauch \& Co., Braun \& Blanchard, por mencionar sólo algunos. La última, por ejemplo, exhibía en el frontis de su edificio un gran letrero con el nombre de la sociedad, de manera que es muy probable que los puntarenenses emplearan dicho nombre para identificar esa zona de la ciudad (véase Fig. 6).

En una etapa intermedia se ubicaban aquellas firmas que seguían combinando un nombre de fantasía con el del propietario -como Farmacia y droguería Magallanes de Enrique Piña, Casa Inglesa de L. L. Jacobs, La Pampa de Hardcastle \& Co., Gran Comptoir Parisien de Claudio Imbert, La Puntarenense de John Esdale, Armería Helvetia de F. Schlaprach o La Mueblería y colchonería La Económica de Francisco Rabaglio- mientras que la identificación de un local con un nombre de fantasía que no individualice a sus propietarios marca una última etapa de esta línea evolutiva. Como ya señalamos, dentro de los escasos establecimientos que ya se identificaban en 1900 con un nombre que funcionaba como marca, estaban Librería Hugo, Panadería Universal, Sastrería Moderna, Droguería y botica Francesa, Herrería Austríaca. Cabe destacar la tendencia, bastante generalizada en el comercio tanto de Punta Arenas como de otras ciudades chilenas, de emplear como marca la procedencia de dueños o fundadores del establecimiento: "Francesa", "Inglesa", "Alemana", "Austríaca". Es el caso de La Casa Alemana (de J. H. A. Wehrhahn), la Droguería y Botica Francesa (de León Marchal) y la Herrería Austríaca (de Depolo y Rustich). Curioso es el caso del denominativo "casa inglesa", ya que figuran al menos tres establecimientos con dicho nombre: el establecimiento de L. G. Dobrée, el de L. L. Jacobs y el de A. Hunter y Cía. Otra tendencia era la de denominar el establecimiento con alguna referencia local, dada por la calle en la que se ubicaba o bien por la zona geográfica del entorno (por ejemplo, "Pampa", "Puntarenense" o "Magallanes"). Al avanzar la década se sumaron otros locales con nombres de fantasía: El Arco

Stubbs \& Co." y en La Unión, 1 de octubre de 1912

28 El Comercio, 12 de febrero de 1907. 
Iris, barraca Centenario, zapatería La Fama, taller Minerva, A la Ciudad de Pekín, Á la Ville de Chicago, carpintería La Independencia, confitería Plompon y talabartería del Caballo Blanco. Las palabras "Casa" o "Ville" (ciudad) eran empleadas, como en otros rincones del mundo, para referirse a establecimientos que tendieron a especializarse en el ramo de las "novedades", o artículos de vestir, algunos de los cuales luego se transformaron en tiendas por departamentos. Si en el Santiago de la época existían Casa Prá, Casa Francesa y Ville de Nice, en Punta Arenas se hallaban Casa Inglesa, la Ciudad de Pekín y la À la Ville de Chicago. Sin embargo, no todos aquellos locales lograron dar el salto y transformarse verdaderamente en grandes tiendas. De hecho, sólo la primera continuó insertando avisos en la prensa magallánica al comenzar la segunda década del siglo, haciendo referencia a la existencia de distintos departamentos ${ }^{29}$.

Con respecto a los productos en venta, también es posible hallar algunos identificados por su marca. De esta manera, en la forma de envases rotulados y avisos impresos en la prensa múltiples marcas ingresaron a la intimidad del hogar y al imaginario de los puntarenenses. Si bien la primera ley de marcas chilena data de 1874, no fue sino hasta diez años más tarde que se registró la primera marca de fábrica (Álvarez, 2008, p. 74). Sin embargo, muchos de los productos que llegaban a este puerto austral provenían de países como Francia, Alemania e Inglaterra, cuya legislación y tradición en relación con las marcas tenía un más largo recorrido, de modo que varias marcas se habían ido instalando en las estanterías y aparadores de los locales comerciales de la ciudad ${ }^{30}$. En los avisos del año 1900 sólo hallamos los de desinfección de ovejas y lana, de whiskies y otros licores, tabaco y chocolates... todos ellos importados desde Inglaterra o Francia. Sin embargo, la tendencia a identificar cada producto con una marca se fue intensificando en la medida en que fueron pasando los años. En 1914, por ejemplo, aparecen los polvos desinfectantes Cooper, el

29 Véase el aviso de L. L. Jacobs en The Magellan Times, 7 de diciembre de 1921.

30 En Francia se habían hecho avances en contra de la falsificación en 1803 y luego en 1810, aunque una ley que gramófono Grammavox, la cámara Kodak, la máquina de escribir Remington, coches y autos Ford, Studebaker, cigarrillos y/o tabaco Capstan, Black Cat, Jetty, Golden Cypher, Golden Gross y Three Castles; la pintura Empirite, los whiskies Buchanan y Gaelic, y los vinos Santa Rita, Santa Elena y Vial. Tres años más tarde, en tanto, se han sumado otras marcas nacionales, como agua mineral Jahuel y Panimávida, además de las extranjeras de whisky Munro y las líneas Royal Household, Black and White y Red Seal en los Buchanan; los binoculares Zeiss; en automóviles se agregan Cadillac, Jeffrey, Buick y Hupmobile, además de los neumáticos Stepney y Firestone, bicicletas Hirondelle y las motocicletas Harley-Davidson. Para el área de la construcción, aparecen el cemento Ancla y el Internit, y para la industria lanera siguen los productos Cooper y los polvos Little, además de las prensas hidráulicas Cardwell y Ferrier. Un buen ejemplo del poder creciente que tenía la marca en el ámbito comercial e industrial, se advierte en la campaña que hizo Internit para introducir su producto en Punta Arenas a través de la prensa: los primeros anuncios se limitaban a decir ¿qué es Internit?, para luego, en los meses siguientes presentar el producto y sus características particulares.

\section{Los valores}

Del mismo modo que la mayor o menor presencia de marcas en los avisos es indicador de cuestiones mucho más complejas, el tipo de argumentos que utilicen para persuadir al posible consumidor también es signo que debe tenerse en cuenta por los datos, pistas y preguntas que arrojan. Una manera de abordar el estudio de los argumentos publicitarios tiene relación con los valores a los que apelan. Si bien este asunto ha sido estudiado con gran interés desde la década de los cincuenta, fueron los trabajos de Richard Pollay en los ochenta los que reactivaron el interés en este aspecto: tras identificar 42 valores ampliamente aceptados

acogiera todo un sistema asociado al registro y protección de las marcas fue de 1857; lo que en Alemania debió esperar hasta 1874 y en Inglaterra hasta el año 1905. 


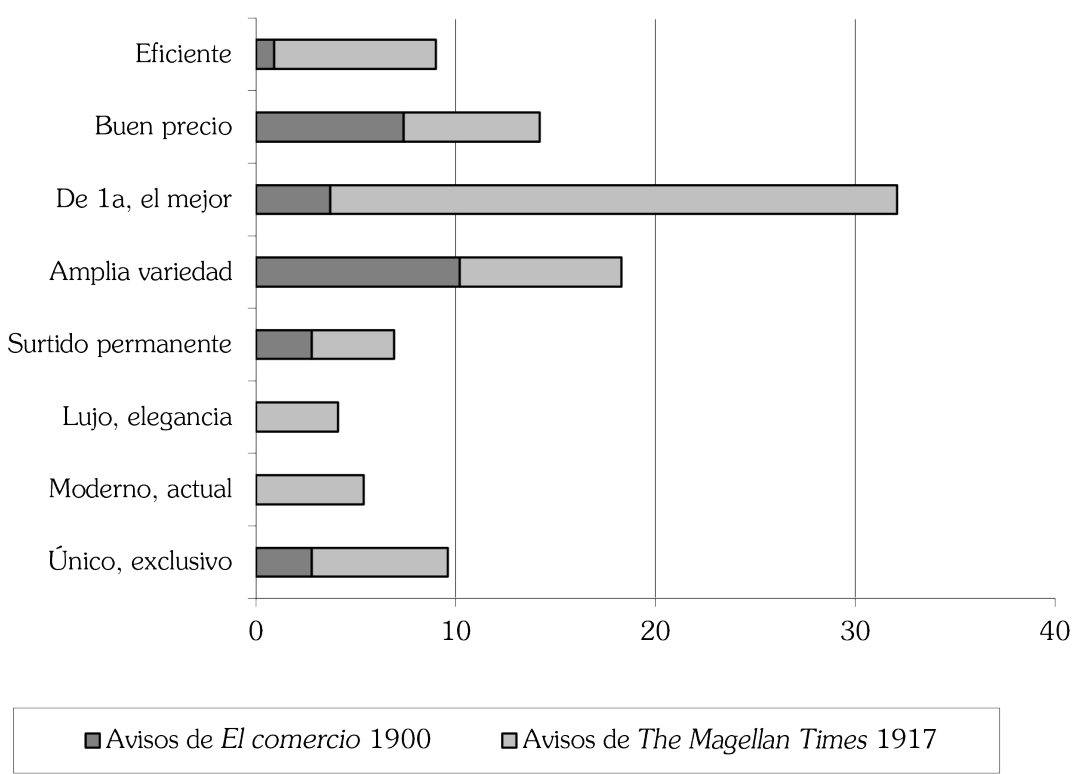

Fig. 7. Valores más empleados en los avisos de El Comercio (1900) y de The Magellan Times (1917).

en tres países, llegó a la conclusión de que la publicidad refleja sólo algunos de ellos, lo que se ajusta a las características del público al que se dirige (Pollay, 1987, pp. 104-109). Trabajos posteriores, como el de Lucía Domínguez y de Alfonso Méndiz (Méndiz, 2010, pp. 24-35), han permitido completar y clasificar con más precisión el listado de valores que aparecen en la publicidad. Para este estudio se tuvieron en cuenta estas propuestas en una fase final, ya que se comenzó por analizar los avisos extraídos de El Comercio de 1900 y The Magellan Times de 1917 con el fin de identificar los valores empleados en sus discursos. Se tuvo especial cuidado con el lenguaje y los adjetivos empleados, ya que proporcionan señales sugerentes para la historia cultural en general, y del consumo en particular (Fig. 7).

Si bien debe admitirse de que se trata de dos periódicos diferentes en cuanto a su naturaleza y probablemente también a su público objetivo, lo que puede traducirse en la práctica en un cierto margen de error en el ejercicio comparativo, de todas maneras, permite hacerse una idea de lo que los receptores de los anuncios valoraban, al menos desde la mirada de los avisadores. Así, es posible suponer que a los puntarenenses de 1900 y de 1917 lo que más les importaba era el buen precio y la amplia variedad de productos que ofrecían los establecimientos comerciales. Apelar al precio no parece algo que merezca mayores comentarios, pues suele ser junto a la marca uno de los recursos más empleados por la publicidad. Sí llama la atención la insistente recurrencia al argumento que apela a la "amplia variedad" de productos, pues ello cobra especial sentido en una ciudad alejada del resto del país y cuyo abastecimiento se hacía básicamente por vía marítima. De hecho, si eso se asocia a otro recurso muy empleado, el de destacar la existencia de un "surtido permanente", permite conjeturar que no fuera algo extraño para los habitantes de Punta Arenas que ciertos productos desaparecieran del mercado de tanto en tanto de modo que se hiciera necesario esperar hasta que algún local insertara un anuncio con la fórmula "llegó un surtido de...". En cambio, calificar el producto ofrecido de lujoso, elegante, exclusivo o único no pareció importar mucho a la sociedad magallánica de 1900 , pero sí se constituyeron en argumentos relevantes para el año 1917. Visto desde otra perspectiva, el grueso de la publicidad estudiada invocó principalmente la calidad del producto empleando para ello términos como "bueno", "eficiente", "el mejor" y de "primera clase", 
lo que coincide con nuestras apreciaciones en estudios anteriores hechos con ejemplos capitalinos (Dussaillant, 2011, op. cit. p. 260). En contraste, la publicidad puntarenense prácticamente no apeló a los usuarios, como ya hacían muchos avisos en otros periódicos de la época mediante alusiones laudatorias hacia el potencial consumidor. La única excepción encontrada durante todo el período fue el anuncio del jabón de lavar Sunlight que calificó a sus potenciales usuarias como "buenas dueñas de casa".

Por último, si se asocian los valores identificados con la metodología de análisis propuesta por Domínguez, resulta que los avisos de la prensa magallánica en 1900 tenían mayor inclinación a lo que ella denomina "valores colectivos", mientras que hacia 1917 ya aparecen algunos "valores del yo", más vinculados a sociedades hedonistas, como el lujo o la ostentación. Si se toma la escala de Méndiz, en tanto, podría decirse que los avisos magallánicos de 1900 respondían a "instintos más primarios de los seres humanos", como la facilidad de uso (Méndiz, 2010, op. cit. p. 29), que se relaciona con "necesidades primarias". Esto es que aquello que se desea (el producto) sea accesible, tanto por disponibilidad permanente en el mercado como por precio, y que su calidad responda a la necesidad (eficiencia, el mejor). En otras palabras, este ejercicio pareciera sugerir que los puntarenenses de 1900 estaban inmersos en un ambiente de consumo precario, en el que se valoraba más la utilidad del producto que aquellos elementos simbólicos que más adelante serían asociados a él. En 1917, en tanto, si bien lo anterior seguía siendo relevante, la aparición de los valores asociados al lujo, elegancia y modernidad parecen sugerir que el consumidor comenzaba a visualizar significados que trascienden al producto en sí, pero que son aquellos que la publicidad empezó a vincular a cada marca. Un buen ejemplo de este cambio son los anuncios publicados en The Magellan Times en 1917 de dos marcas de un producto similar. En el primero, del producto Acaroína, se llamaba la atención del lector con un aviso que combinaba el dibujo de un numeroso grupo de ovejas muy cargadas de lana, con un texto

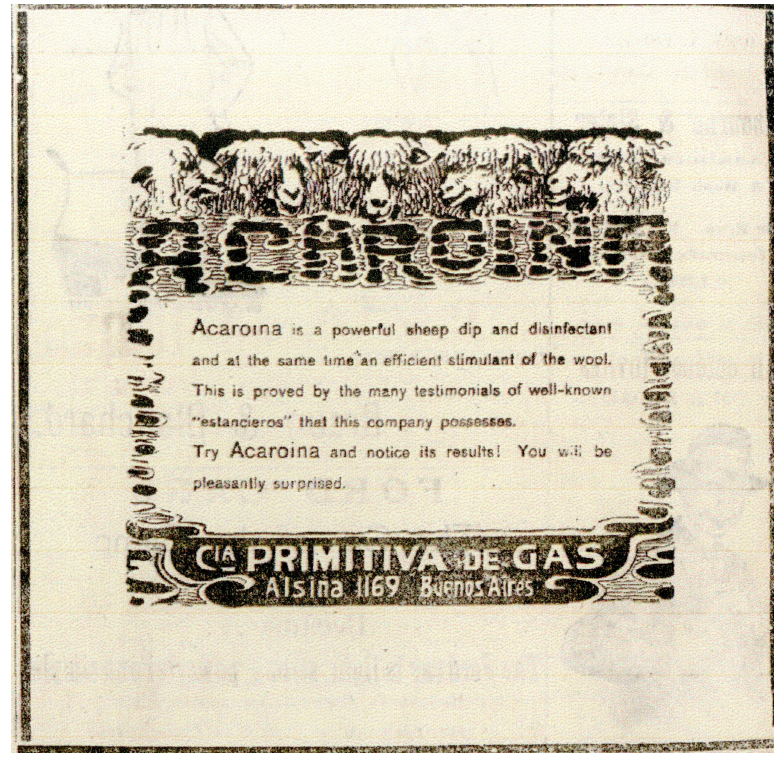

Fig. 8. The Magellan Times, 1917.

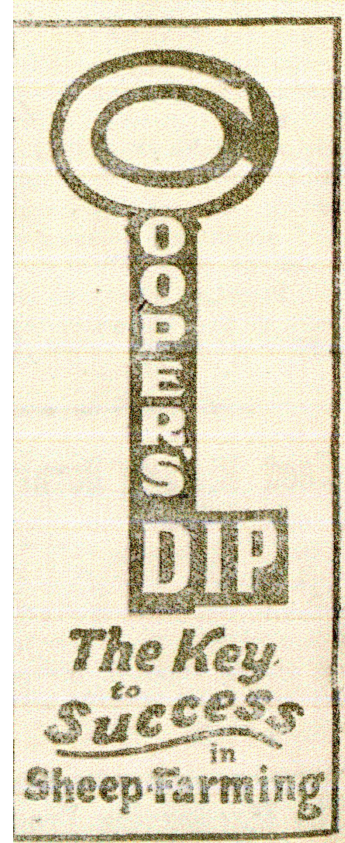

Fig. 9. The Magellan Times, 1917.

que enfatizaba en la eficiencia del desinfectante (Fig. 8). El otro, en tanto, correspondiente a Cooper's Dip (Fig. 9), recurre a la imagen de una simbólica llave acompañada de un escueto pero elocuente texto que busca vender mucho más que un desinfectante: la llave al "éxito" empresarial. 


\section{CONCLUSIONES}

Tomando en consideración el hecho de que la publicidad tiene por función informar $y$ persuadir, es fundamentalmente en un escenario de competencia comercial donde realmente es puesta a prueba su creatividad con el objeto de hacer del lector un comprador. En los ejemplares revisados, los avisos tenían un énfasis informativo, pero indudablemente ya empleaban recursos más sofisticados, lo que sin duda se dio a la par con el desarrollo industrial y comercial de la zona, y con los consiguientes cambios en los hábitos de consumo de la sociedad magallánica. Los aportes de los avisos publicitarios no terminan con la valiosa información explícita acerca de establecimientos y productos. Existe mucha información que debe obtenerse "leyendo entrelíneas", es decir, que exige un mayor grado de atención, elaboración $e$ interpretación y que puede entregar invaluables datos, pistas y preguntas al historiador. Para el caso la prensa magallánica estudiada evidentemente quien conoce la historia de la zona, sus principales actividades económicas, las características sociales y de las colonias extranjeras residentes, podrá plantear mejores "preguntas" a cada aviso. Los avisos también proporcionan detalles aparentemente insignificantes que, sin embargo, pueden resultar de interés para muchos estudios, tales como horarios de atención de profesionales y locales comerciales (que podría servir a la historia del trabajo), referencias de precios (relevante para la historia del comercio y del consumo), numeraciones de calles y localización de diversos establecimientos (para historia urbana) y hábitos de higiene (historia cultural o historia de la vida cotidiana). A propósito de esto último, por ejemplo, se vio en los avisos de los hoteles que los huéspedes se bañaban... aunque desconocemos la frecuencia. Pero el anuncio del champú Secret of the Orient que decía que para tener el pelo limpio había que lavarlo una vez a la semana, lo que también ayudaba a combatir la calvicie y la caspa, nos puede servir de referencia.

Dado que con el tiempo fueron aumentando los anuncios que incorporaban imágenes, es posible conocer no sólo algunos productos y sus marcas, sino que también ver diferentes modelos y en sus contextos de uso. Es el caso de un anuncio de À la Ville de Chicago que en 1908 insertó una página completa con imágenes de productos a los que los puntarenenses podían acceder, tales como coches, carruajes, berlinas, coches de guagua, mesas, roperos, aparadores, e incluso un escusado, un bidet y un lavatorio, artefactos que suelen ser muy difíciles de hallar en otras fuentes pero que permiten inferir cómo eran los baños de las casas más acomodadas de la época.

Por último, para interpretar adecuadamente la información que proporciona la publicidad, se debe conocer el contexto histórico en el que se inserta, como también el grado de desarrollo de la actividad en sí, de manera de ser capaz de detectar y distinguir ciertas convenciones. La razón de lo anterior es que, como en cualquier documento histórico, interesa lo que dice, pero también la manera en que lo hace y aquello que omite. Por ejemplo, al revisar los días 18 de septiembre de 1914 y 1917 de The Magellan Times, no existe ninguna alusión a la fiesta nacional en los anuncios publicitarios. Esto podría explicarse con razones que van desde la ignorancia a la indiferencia, desde la irrelevancia a la agresión. Sin embargo, el conocimiento de las prácticas publicitarias de la época nos señala que se compraba un espacio en el periódico para insertar un aviso por un período determinado, por lo que el mismo anuncio podía aparecer sin modificación alguna durante un año $e$ incluso más y, por lo tanto, ello podría explicar que hicieran caso omiso a la contingencia.

\section{AGRADECIMIENTO}

Este trabajo fue escrito gracias al financiamiento otorgado por el Concurso de Investigación Interno (CAI 2016) de la Universidad Finis Terrae.

\section{FUENTES DE CONSULTA}

\section{Fuentes primarias impresas: periódicos}

El precursor de 'El Magallanes' (Punta Arenas) 1893.

El Comercio (Punta Arenas) 1900, 1907.

Chile Austral (Punta Arenas) 1908.

La Unión (Punta Arenas) 1912.

Eco de la Guerra (Punta Arenas) 1914.

The Magellan Times (Punta Arenas)1914, 1917, 1921. 


\section{Fuentes primarias impresas: censos y anuarios}

Comisión Central del Censo (1907). Memoria presentada al Supremo Gobierno por la Comisión Central del Censo. Santiago: Comisión Central del Censo.

Dirección General de Estadística (1925). Censo de población de la República de Chile de 1920. Santiago: Imprenta y Litografía Universo.

Prado Martínez, A. (1905). Anuario Prado Martínez. Santiago: Centro editorial de Alberto Prado Martínez.

\section{BIBLIOGRAFÍA}

Álvarez, P. (2008). Marca Registrada. Santiago: Ocho libros editores.

Arostegui, J. (2001). La investigación histórica: teoría y método. Barcelona: Crítica.

Barthes, R. (1999). La cámara lúcida. Barcelona: Paidós

Bloch, M. (2001). Apología para la historia o el oficio de historiador. México: Fondo de Cultura Económica.

Braudel, F. (2002). Las ambiciones de la historia. Barcelona: Editorial Crítica.

Carr, E. (2011). ¿Qué es la historia? Barcelona: Ariel.

Clampin, D. (2013). Advertising and Propaganda in World War II: Cultural Identity and the Blitz Spirit. In I. B. Tauris (Eds.), Historians at Work: Investigation and Recreating the Past. Sydney: Hicks Smith.

Dussaillant, J. (1993). Breve Historia de los avisos publicitarios en los principales periódicos chilenos. Santiago: Tesis.

Dussaillant, J. (2011). Las reinas de Estado. Consumo, Grandes Tiendas y mujeres en la modernización del comercio de Santiago (1880-1930). Santiago de Chile: Ediciones UC.

Edmundson, A. (2009). History of The British Presence in Chile: From Bloudy Mary to Charles Darwin and the Decline of British Influence. New York: Palgrave Macmillan.

Eguizábal, R. (1998). Historia de la publicidad. Madrid: Editorial Eresma y Celeste Ediciones.

Escandell, M.V. (1996). Introducción a la pragmática. Barcelona: Ariel.

Fox, S. (1984). The Mirror Makers: A History of American Advertising and Its Creators. New York: Morrow.

Gómez García, A. (1914). Viaje de un chileno a Magallanes en 1914. Santiago de Chile: Imprenta Universitaria.

Lantos, G. (1987). Advertising: Looking Glass or Molder of the Masses? Journal of Public Policy \& Marketing, 6, 104-128.

Lara, E. L. (2005). La fotografía como documento históricoartístico y etnográfico: una epistemología. Revista de Antropología Experimental, 5, 2-28.

Leiss, W., Kline, S., Jhally, S., \& Botterill, J. (1986). Social Communication in Advertising. New York: Methuen Publications.

Martinic, M. (2005). La hotelería en el antiguo Magallanes (1870-1950). Magallania, 33(1), 5-24.

McLuhan, M. (2002). The Mechanical Bride: Folklore of Industrial Man. Hamburgo: Ginnko Press.

Méndiz, A. (2010). Los valores de la publicidad: Un Nuevo planteamiento ético y comercial. IC- Media Net Publicaciones.

Moradiellos, E. (1998). El oficio de historiador. México: Siglo XXI.

Packard, V. (1957). The Hidden Persuaders. New York: D. McKay Co.

Pollay, R. (1985). The Subsiding Sizzle: Shifting Strategies in Print Advertising, 1900-1980. Journal of Marketing, 49, 24-37.

Pollay, R. (1986). The Distorted Mirror: Reflections on the Unintended Consequences of Advertising. Journal of Marketing, 50, 18-36.

Pollay, R. (1987). On the Value of Reflections on the Values in 'The Distorted Mirror'. Journal of Marketing, 51, 104-109.

Riego, B. (2001). La construcción social de la realidad a través de la fotografía y el grabado informativo en la España del siglo XIX. Santander: Universidad de Cantabria.

Salkind, N. (1999). Métodos de investigación. México: Prentice Hall.

Sánchez Corral, L. (1997). Semiótica de la publicidad. Narración y discurso. Madrid: Síntesis.

Schudson, M. (1984). Advertising: The Uneasy Persuasion. Its Dubious Impact in American Society. New York: Basic Books.

Souza, M. (2015). Publicidade como fonte histórica: revista da semana. Seminário Comunicacâo e Processos Históricos, Bahía. 